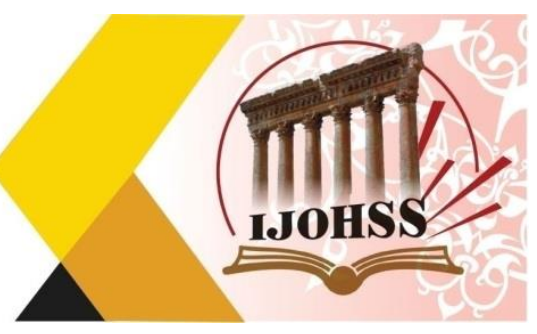

\title{
أسلوب التقرير: مقاربة لسانية تداولية
}

\author{
أ.م.د. كريم عبيد علوي \\ قسم اللغة العربيّة \\ كلية التربية للبنات - جامعة بغداد العربة \\ العراق
}

kareealamere2017@coeduw.uobaghdad.edu.iq

الملخص

يدرس البحث أسلوب التقرير الذي هو حمل الآخر على الاعتر اف بحقيقة ثابتة يريد إنكارها ، وهو من الأساليب التخاطبية الثائعة ، وقد تألف هذا البحث من مبحثين اثنين ، يتضمنُ الأولُ منهما التوقفَ عندَ مفهوم التَّرَير ودلالته المعجمية ومعناه في الاصطلاح النحوي وتحديد علاقته بالاستفهام الحقيقيِّ والاستفهام الاستنكاريٍّ ، أما

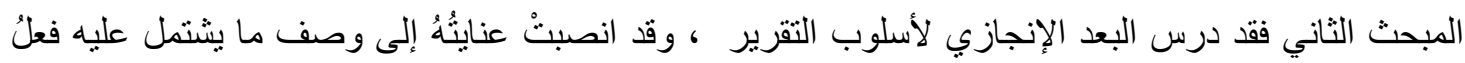
القولِ التقريريِّ من نوزيعِ للمُقَرَرِ به وارتباطه بمفهوم البؤرة ضمن بنية التقرير النحويّة ، وعُنِيَ بالقوة الإنجازية

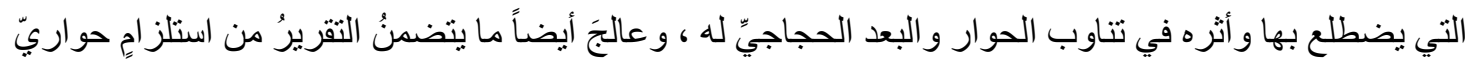

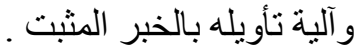
الكلمات المفتاحية: التقرير، الاستفهام، اللسانيات التداولية، الأفعال الإنجازية، الحجاج. 


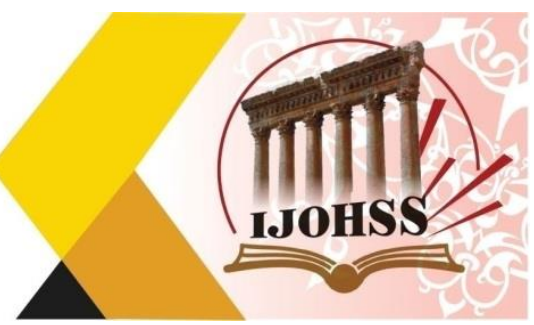

\title{
A Pragma:Linguistic Approach of Confession
}

\author{
Assist. Prof. Dr. Karim Obaid Alawi \\ Arabic Department \\ College of Education for Women \\ University of Baghdad \\ Iraq \\ kareealamere2017@coeduw.uobaghdad.edu.iq
}

\begin{abstract}
This paper is concerned with the pragma-linguistic approach of confession which lets the other admit a fact he wants to deny. It is one of the common conversational methods. This paper is consisted of two sections: the first one discusses the concept of confession, its lexical connotation, its meaning in grammar terminology and determines its relationship with the real and the disapproval interrogation; the second discusses the metaphorical dimension of confession, it also describes the determinative saying verb which distributes the one who receives the confession and its association with the concept of focus within the grammatical structure of the confession. It is also concerned with its performative power and its impact on the rotation of dialogue and its protest dimension. Moreover, it deals with what confession includes of the presupposition talk show and the mechanism of interpreting the affirmative news.
\end{abstract}

Keywords: confession, interrogation, achievement actions, protest dimension. 


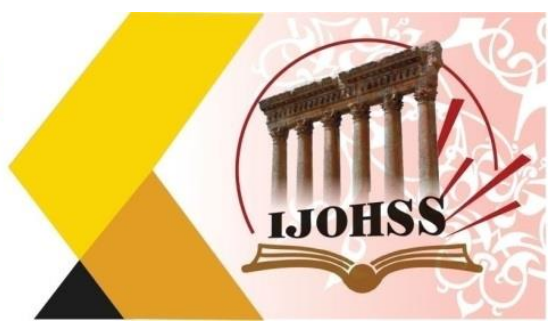

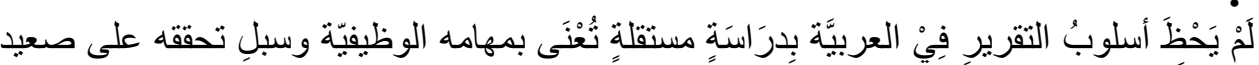

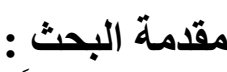

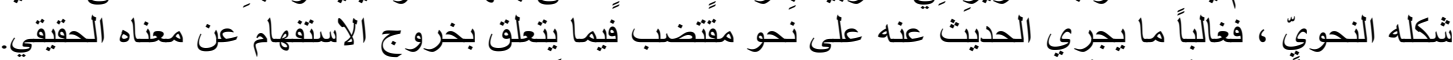

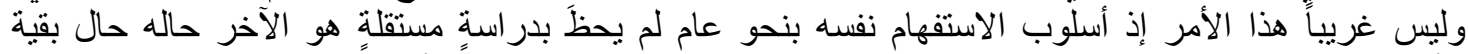

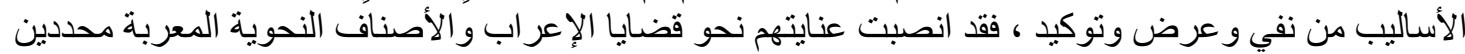

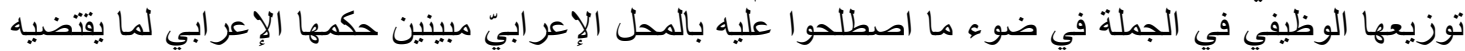

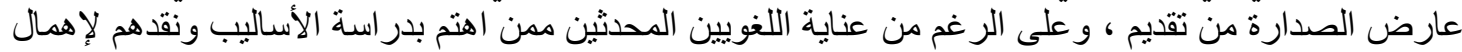

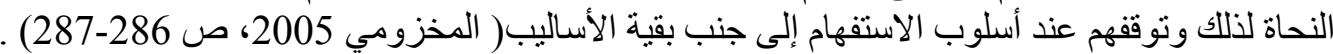

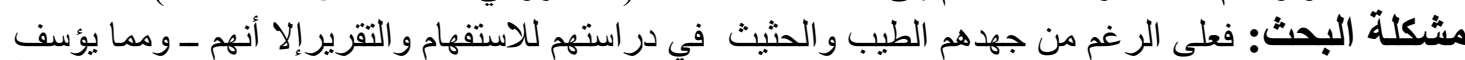

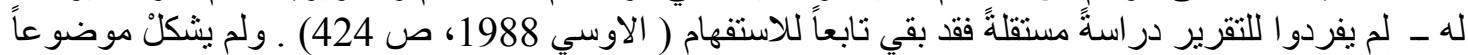

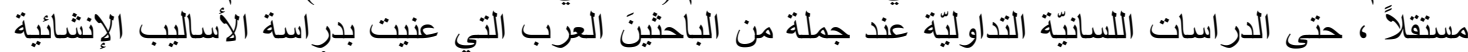

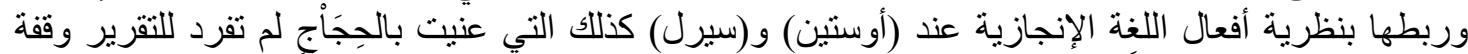

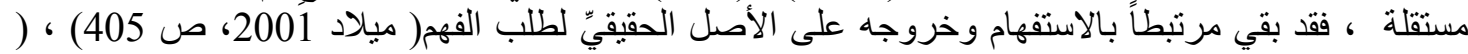

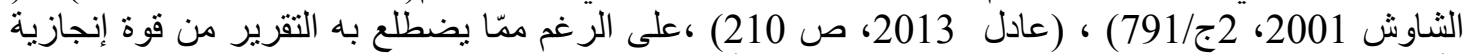

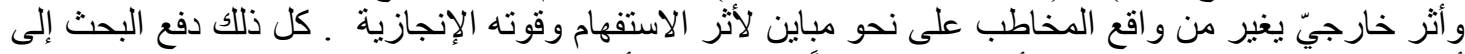

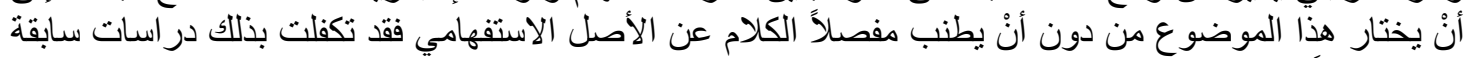

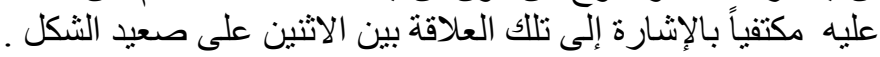

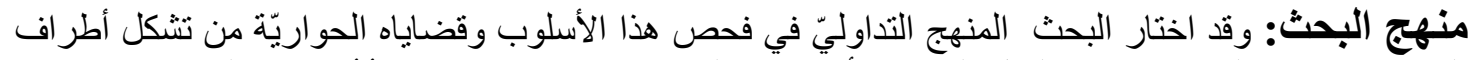

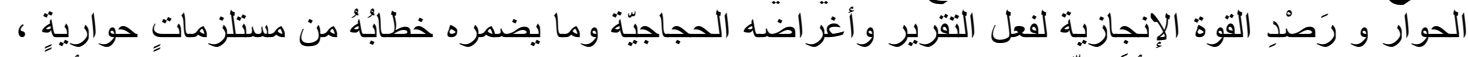

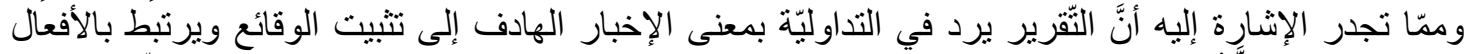

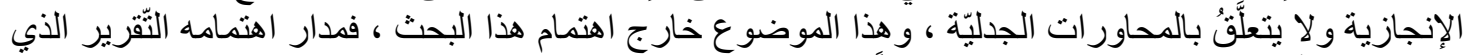

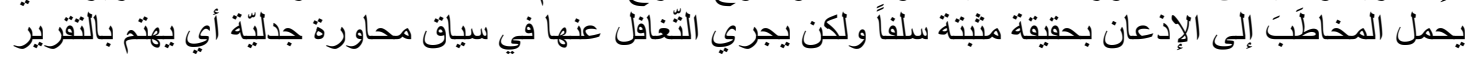

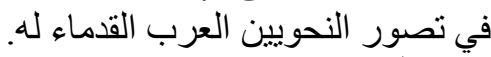
هيكلية البحث: وقد توزعت البحث في مبحثين الاثثين ، انثتمل المبحث الأول على المعنى المعجمي والدلالة

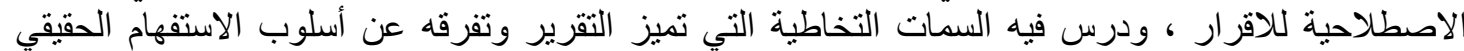

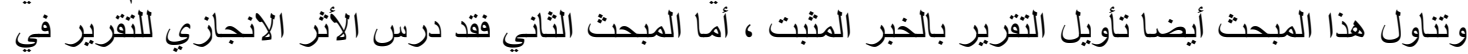

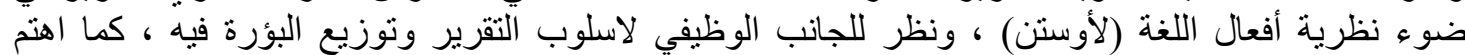

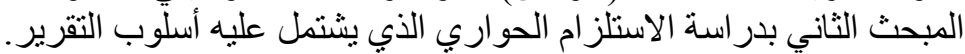

المبحث الأول: علاقة التقرير بالإستفهام

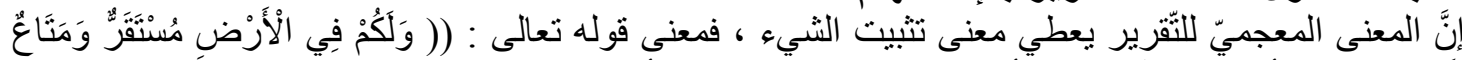

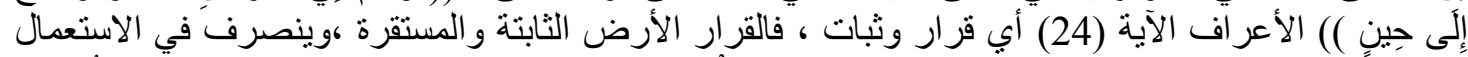

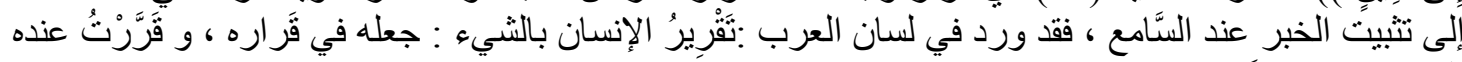

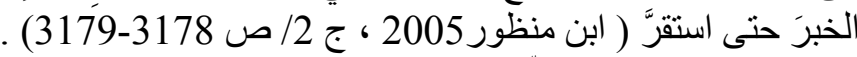

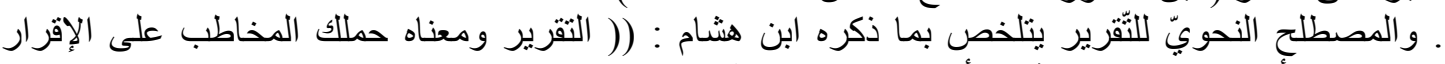

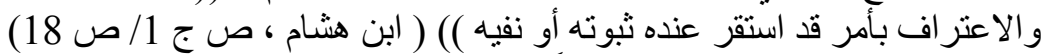

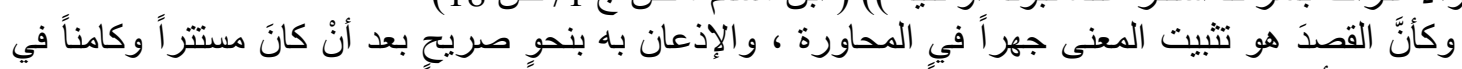

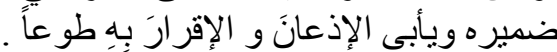

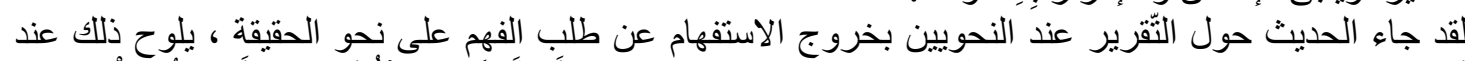

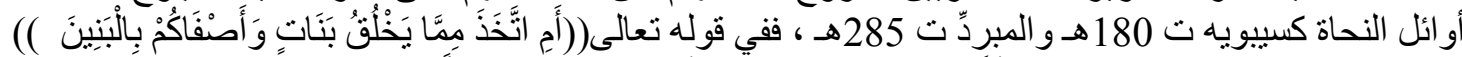

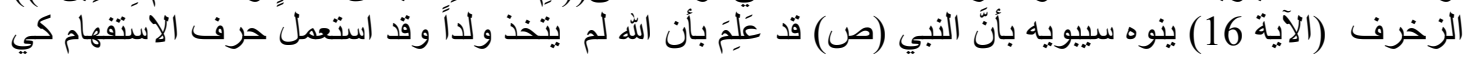




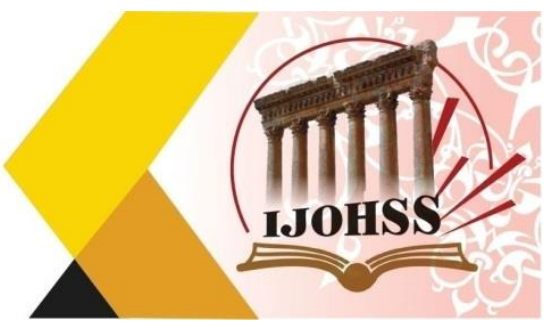

يصرروا ضلالتهم ، نحو قول الرجل للآخر : آلسعادة أحب إليك أم الثقاء ؟ فهو بعلم أنَّ السعادةً أحبُّ إلبه ولكن

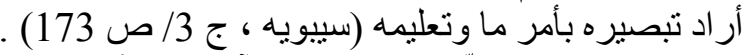

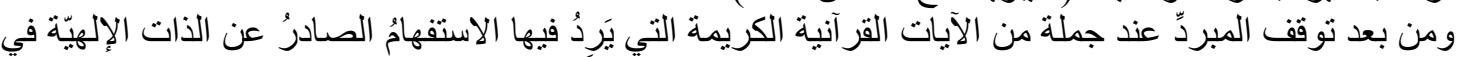

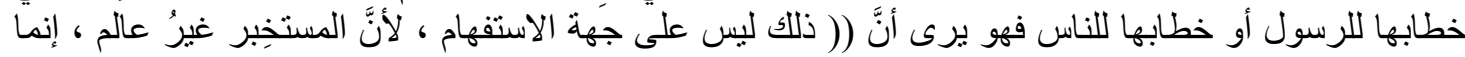

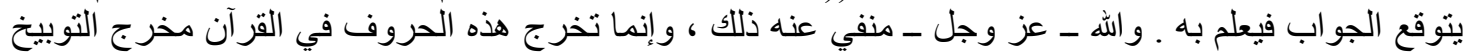

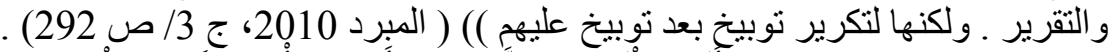

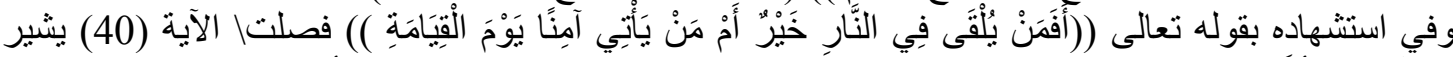

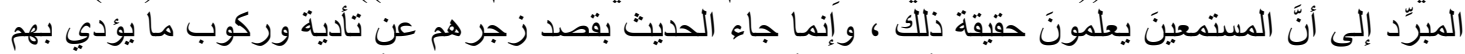

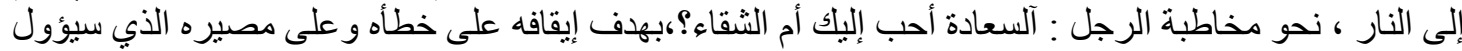

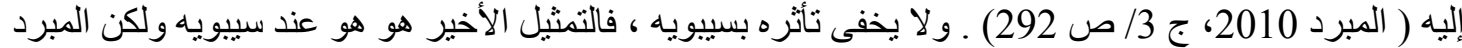

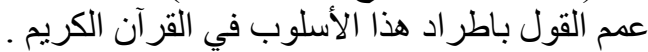

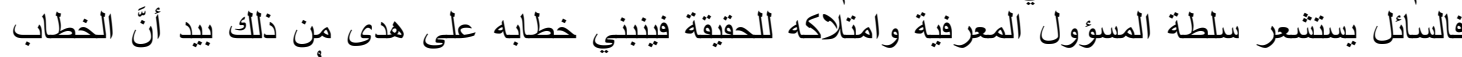

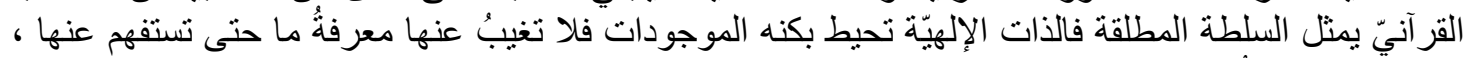

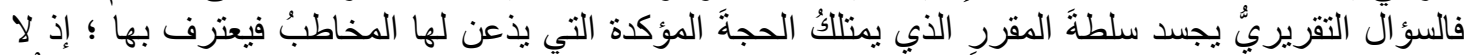

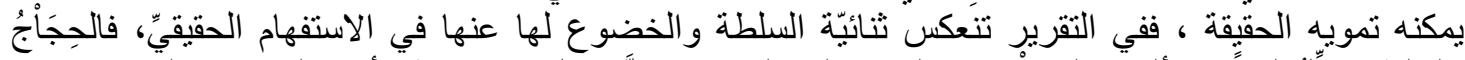

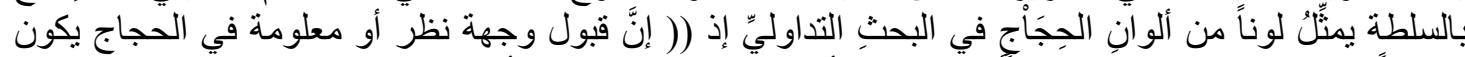

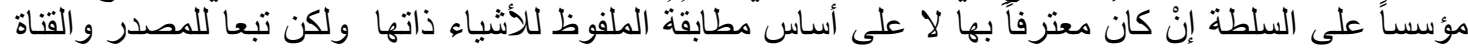

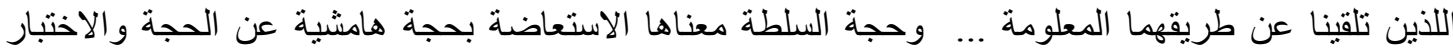

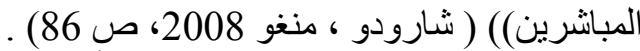

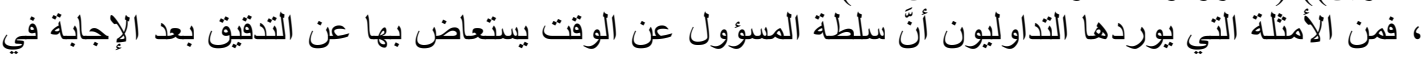

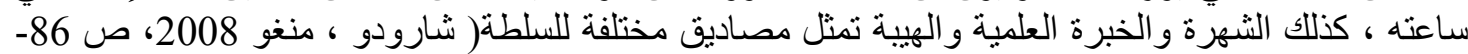

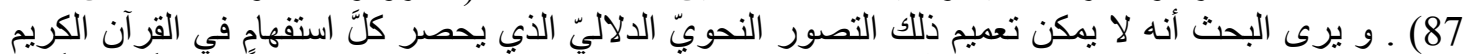

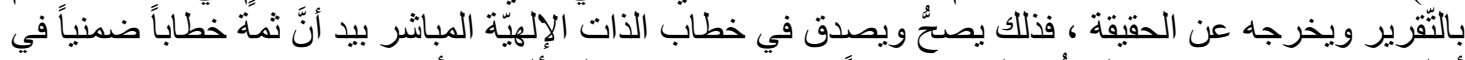

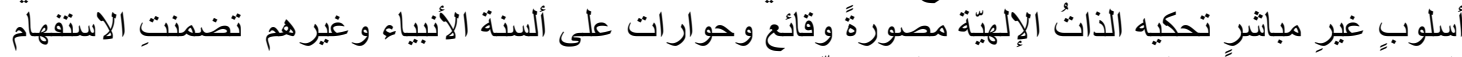

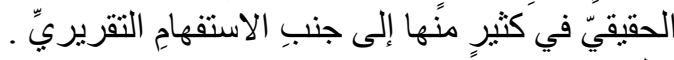

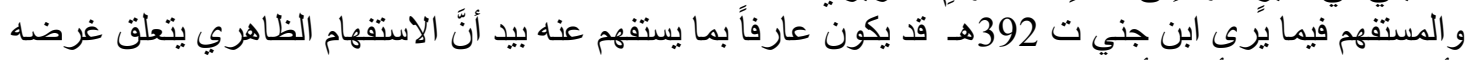

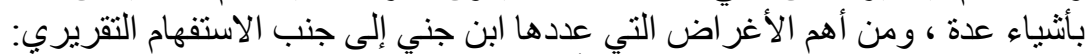

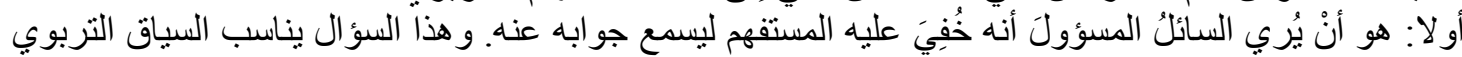

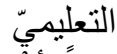

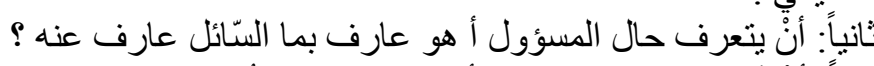

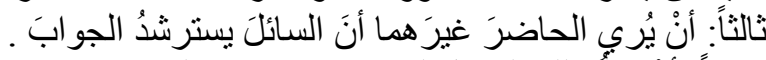

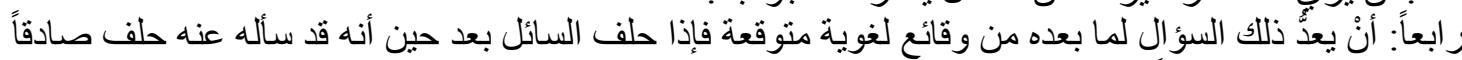

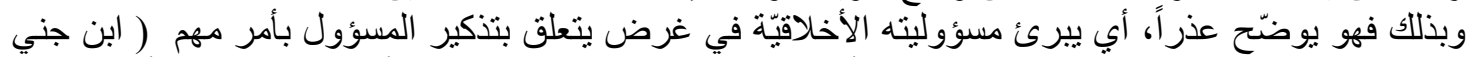

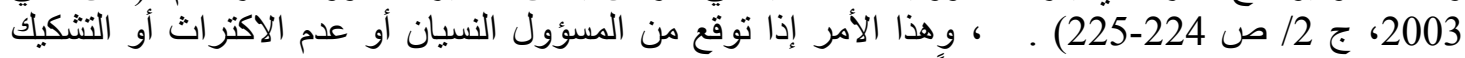

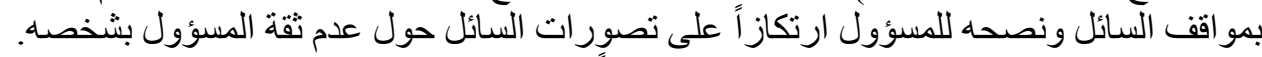

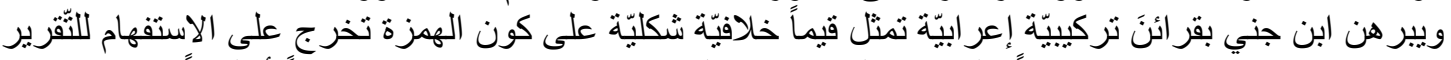

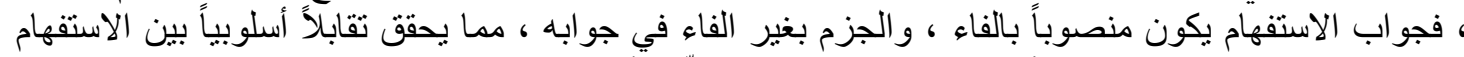

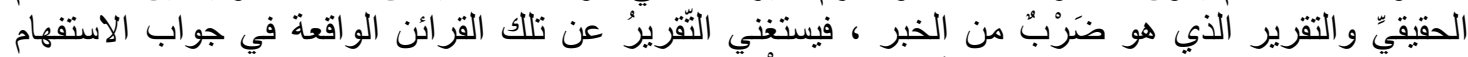

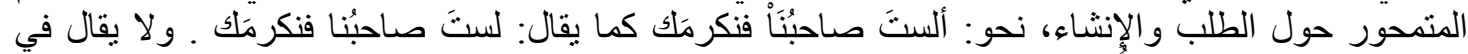

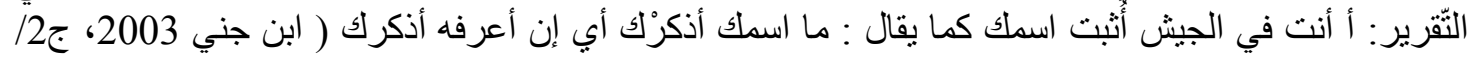
ص (224-223).

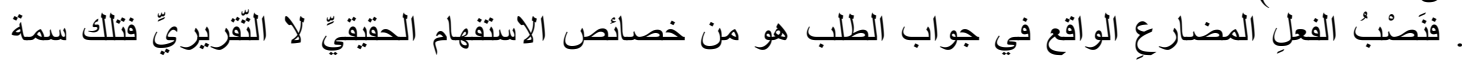




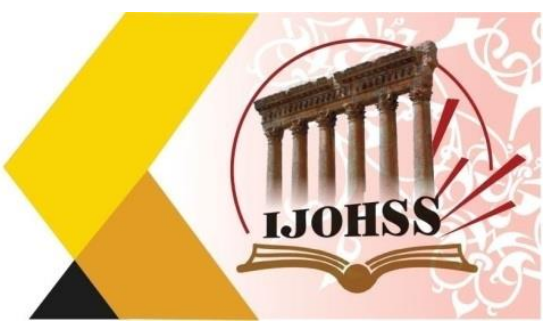

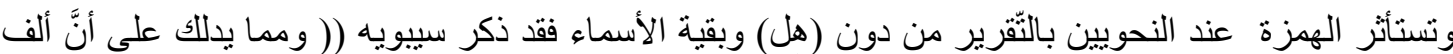

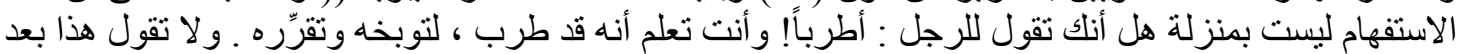

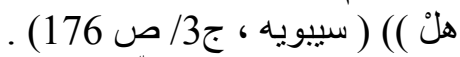

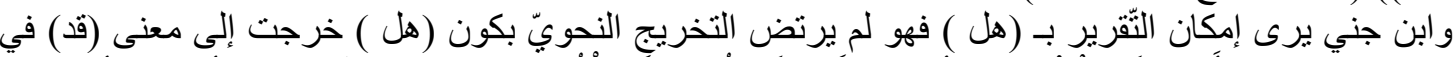

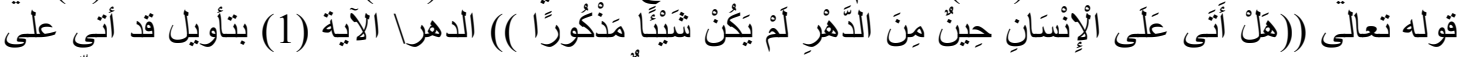

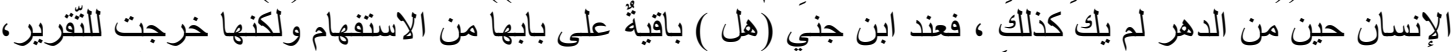

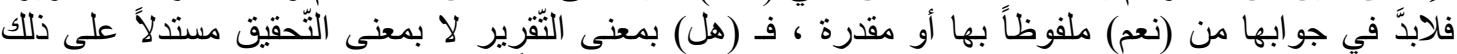

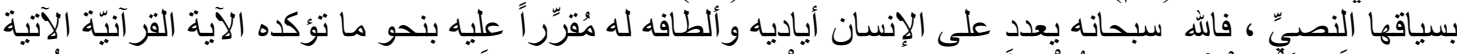

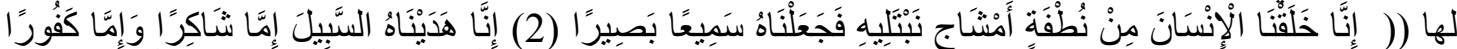

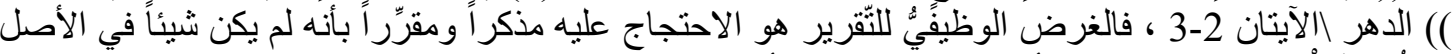

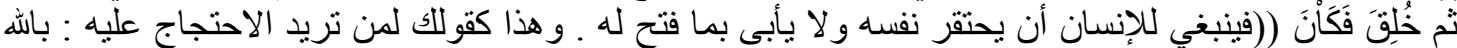

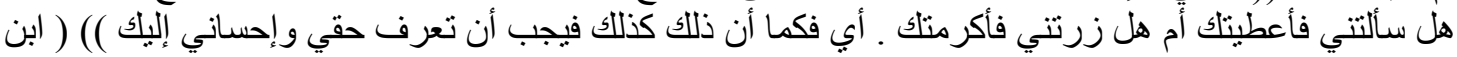

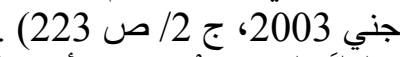

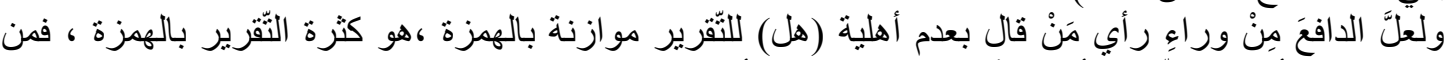

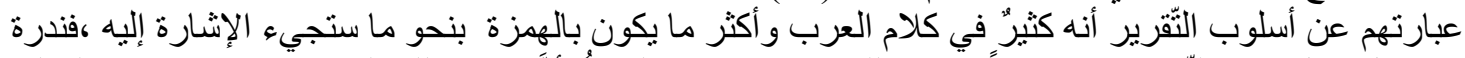

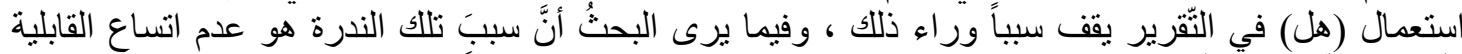

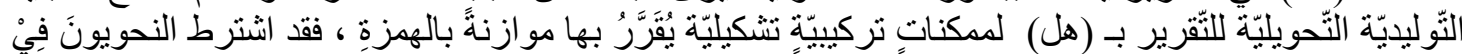

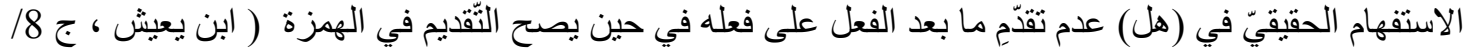

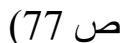

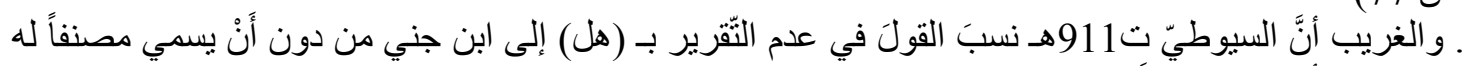

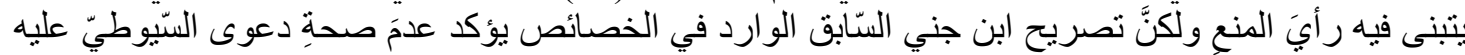

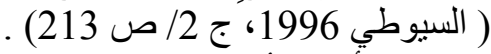

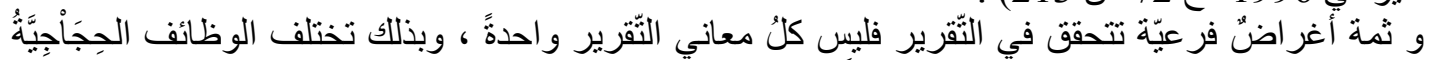

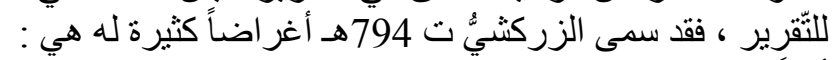

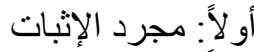

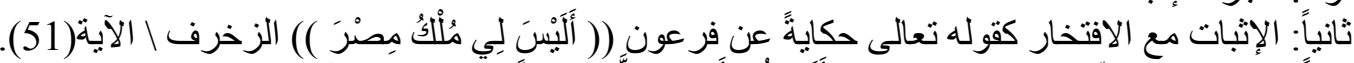

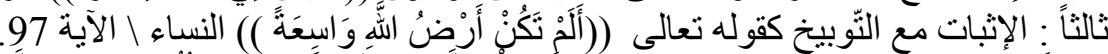

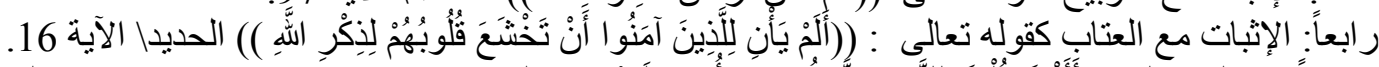

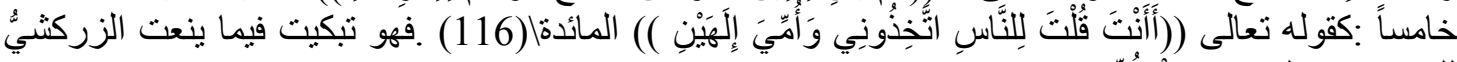

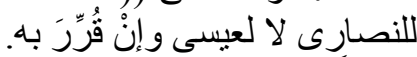

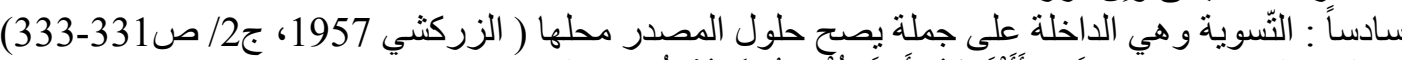

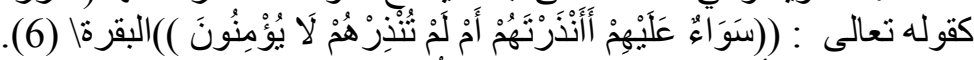

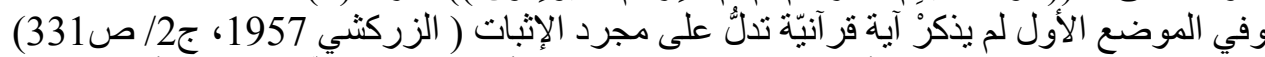

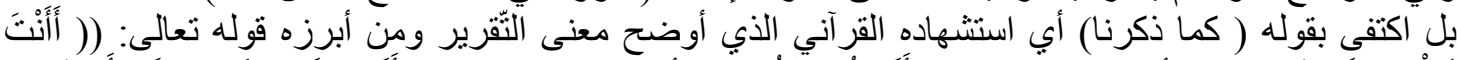

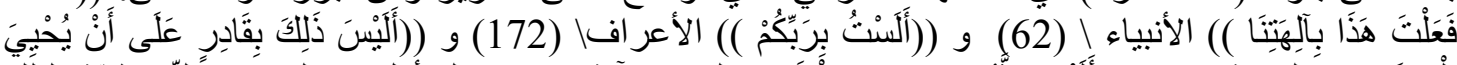

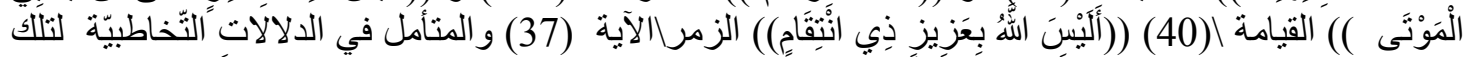

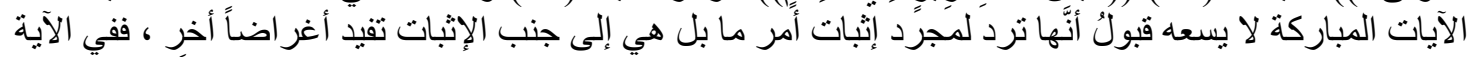

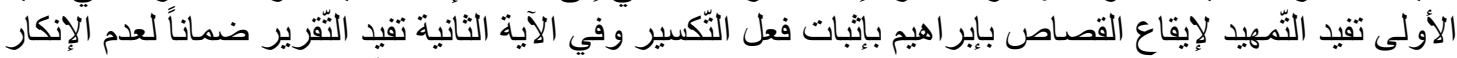

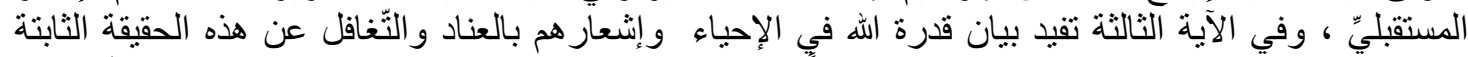

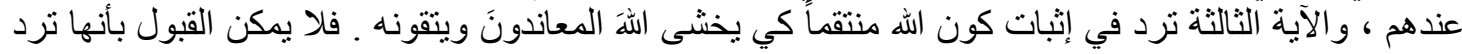

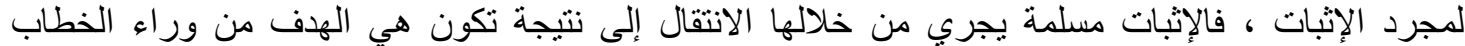

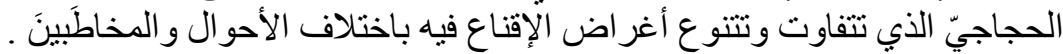




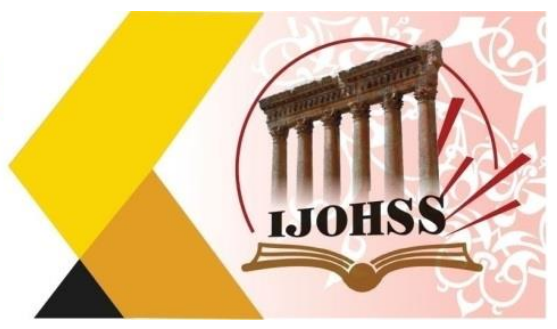

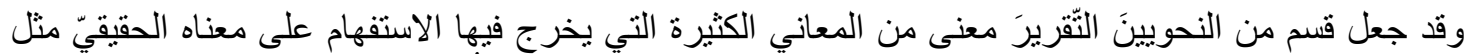

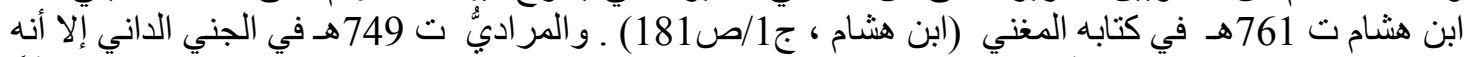

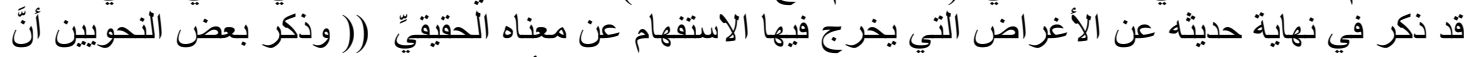

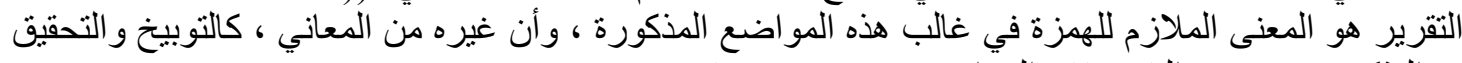

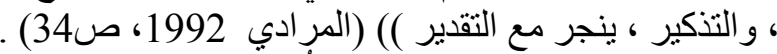

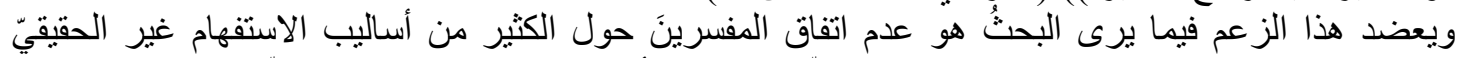

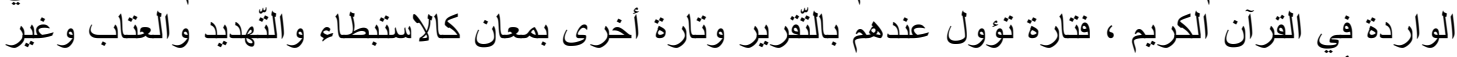

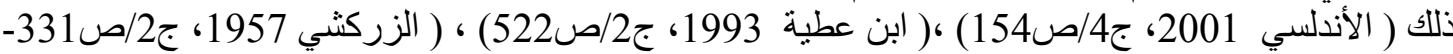

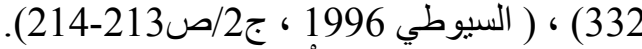

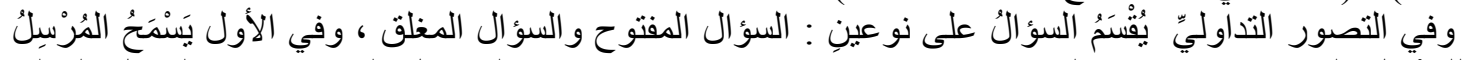

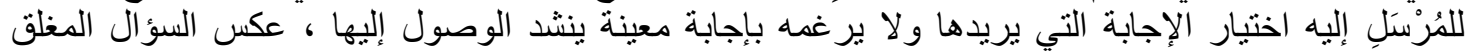

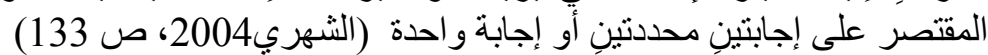

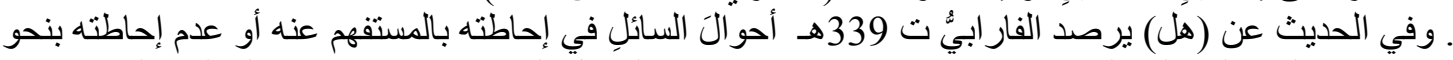

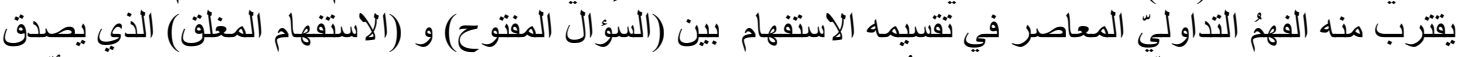

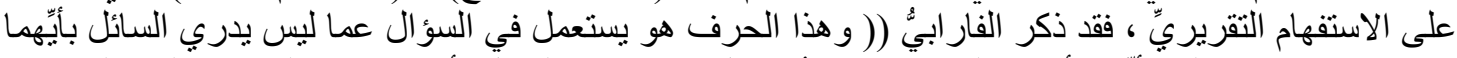

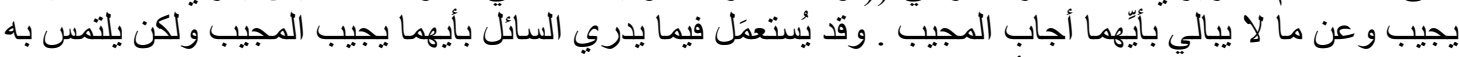

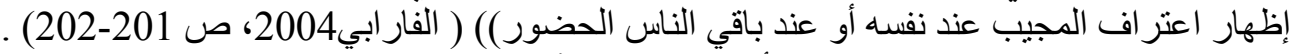

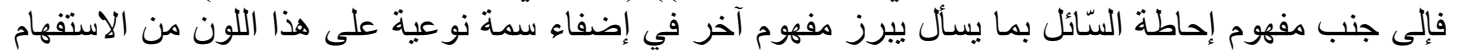

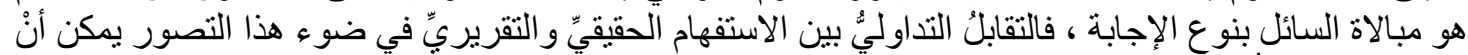

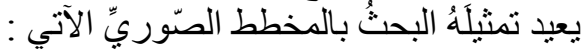

\begin{tabular}{|c|c|c|c|}
\hline \multirow[t]{2}{*}{ |مبالاة السائل بنوع الإجابة } & طلب الفهم & انفتاح السؤال على ممكنات الإجابة & \\
\hline & + & + & الاستفهام الحقيقي \\
\hline+ & & & الاستفهام التقريري \\
\hline
\end{tabular}

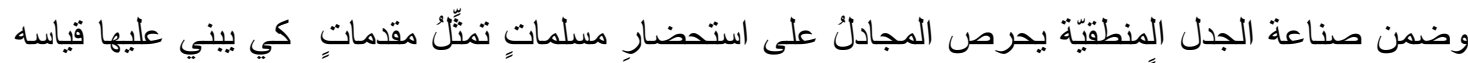

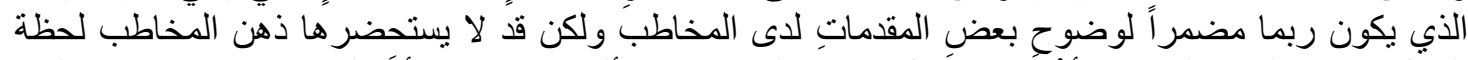

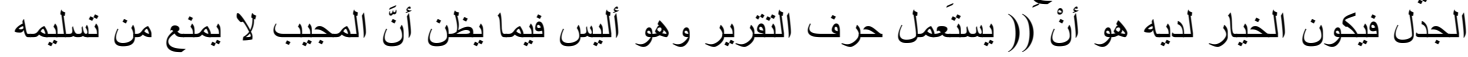

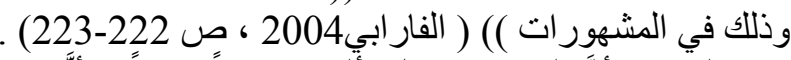

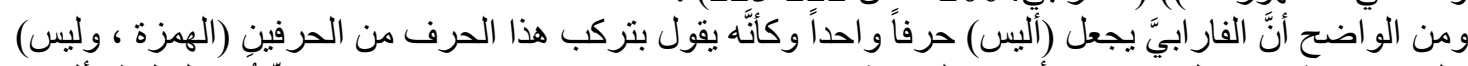

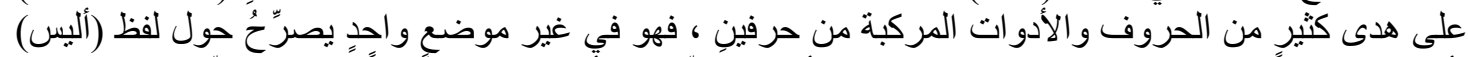

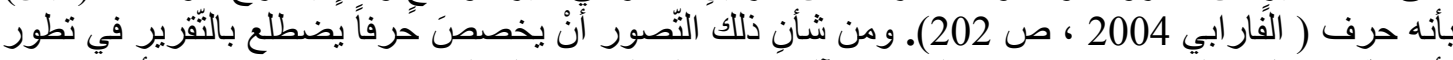

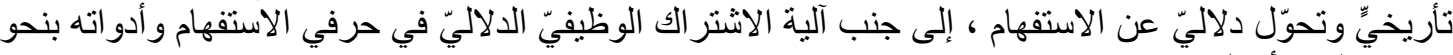

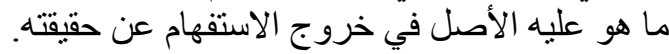

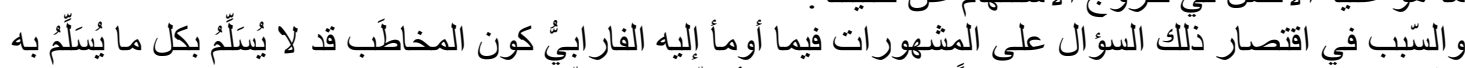

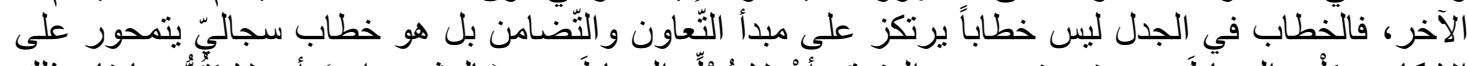

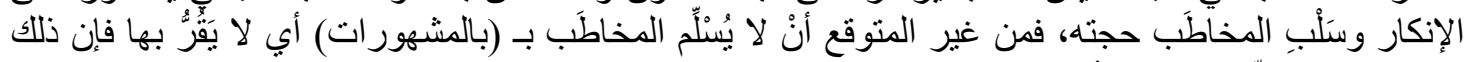

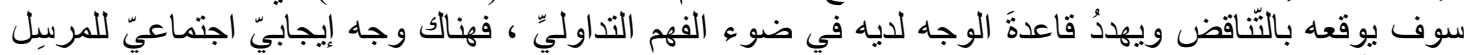

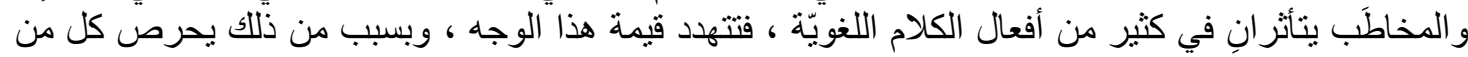




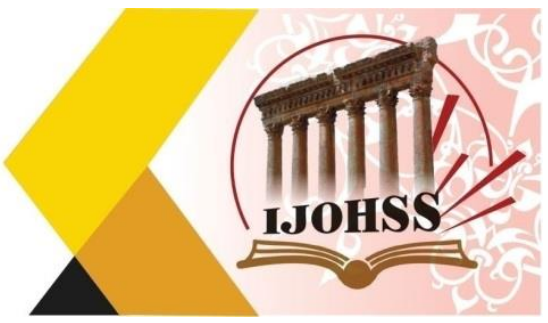

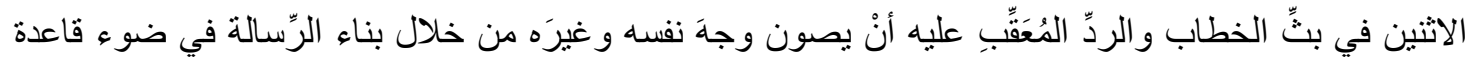

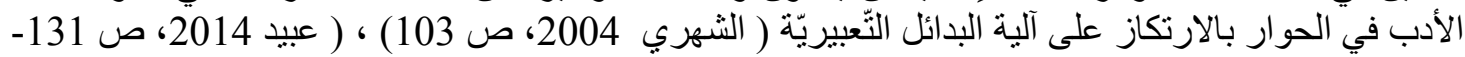

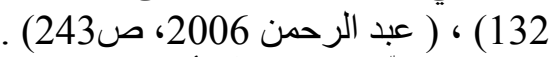

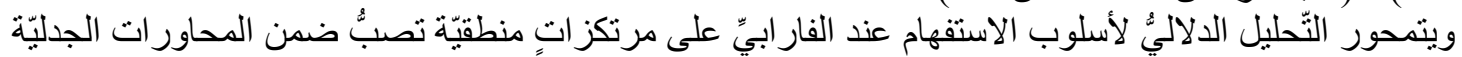

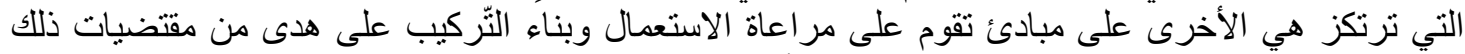

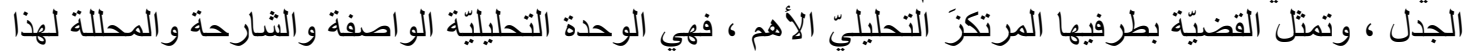

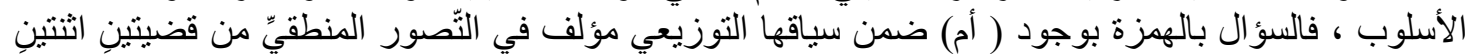

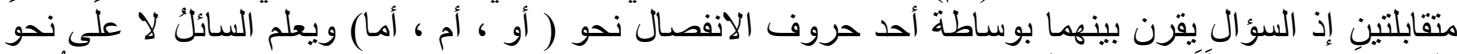

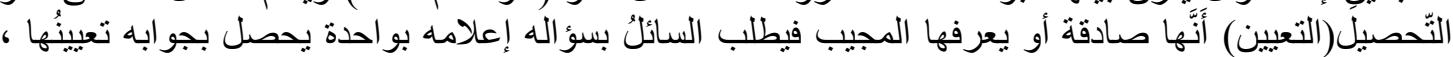

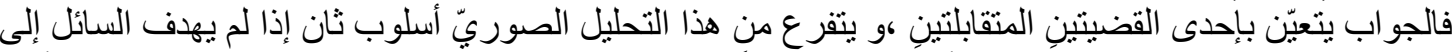

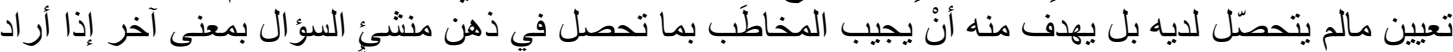

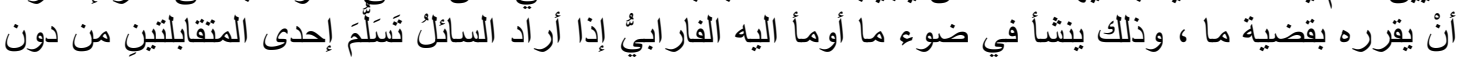

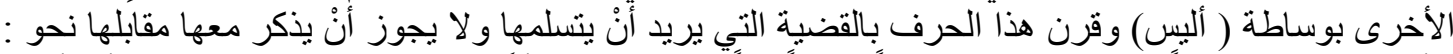

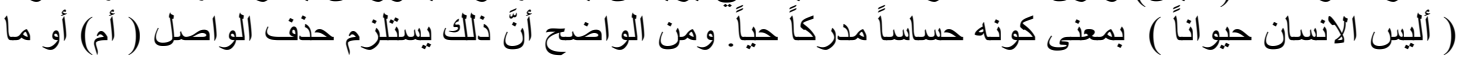

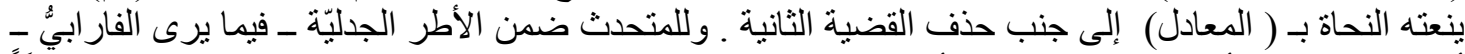

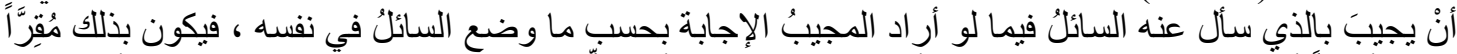

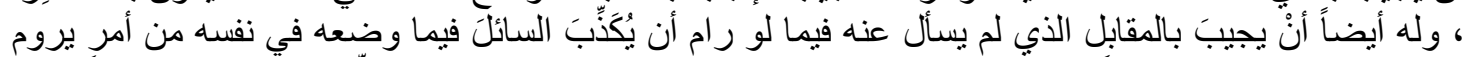

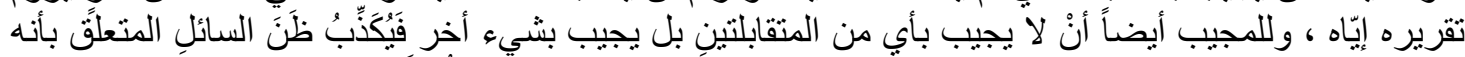

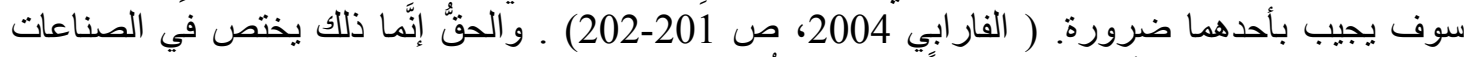

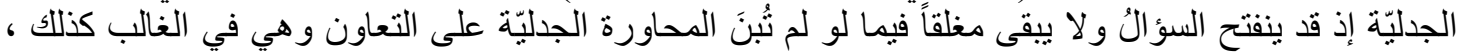

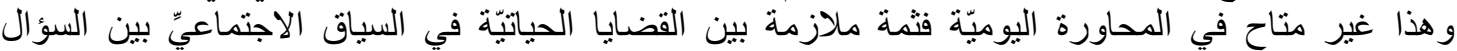

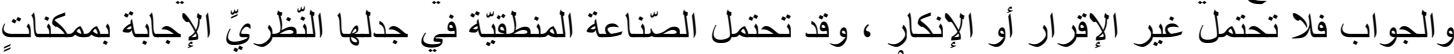

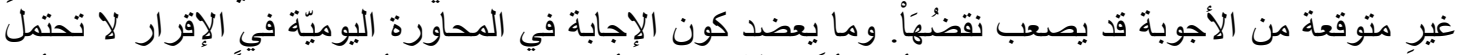

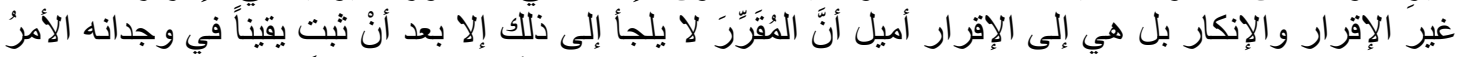

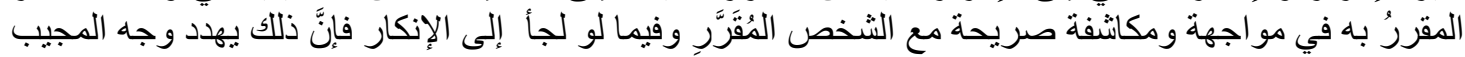
ويضحي بعرى العلاقة بينهما .

تأويل الاستفهام التقريري بالخبر

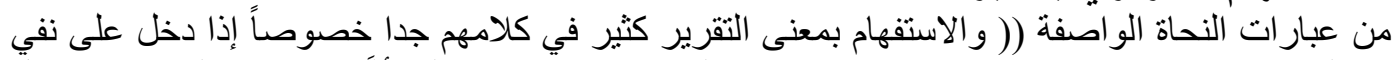

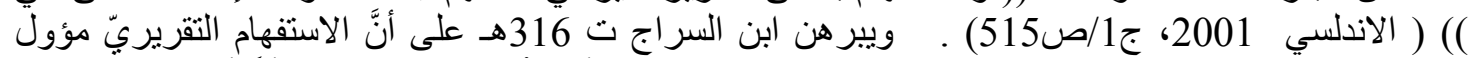

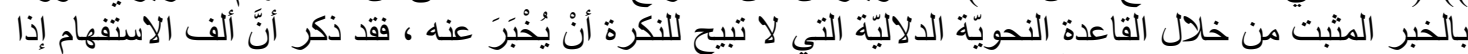

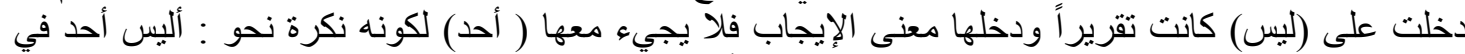

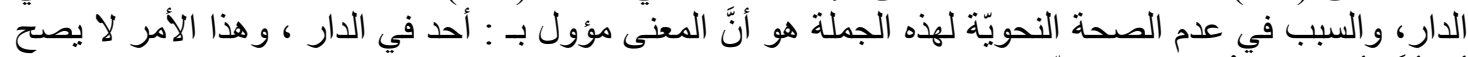

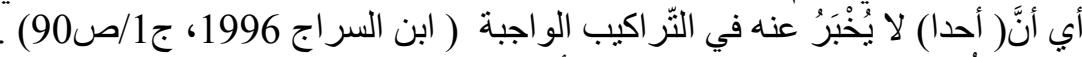

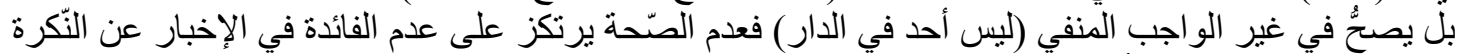

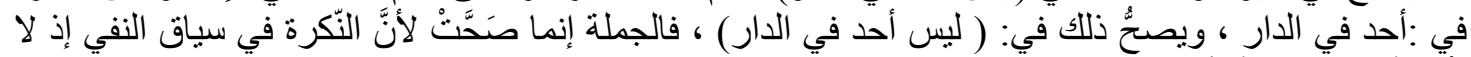

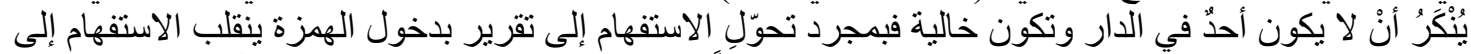

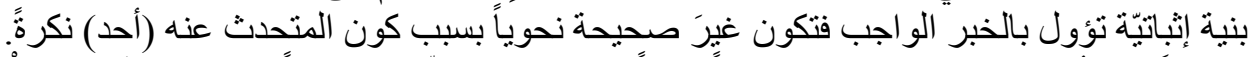

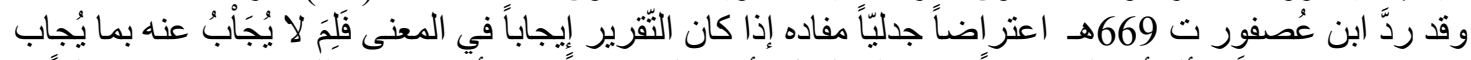

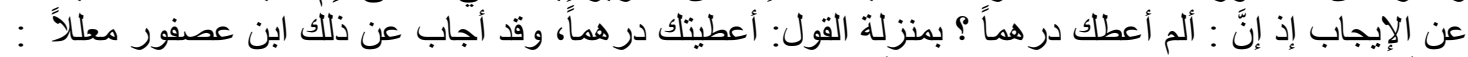

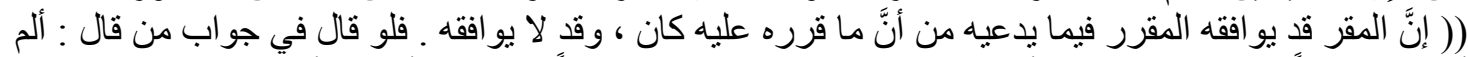

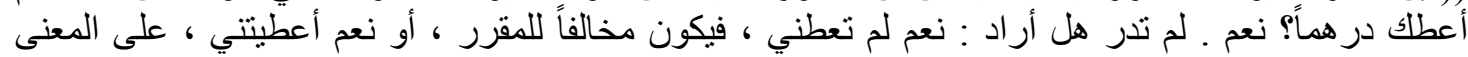




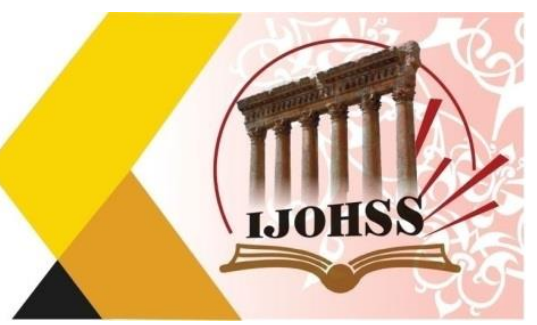

فيكون مو افقاً للمقرر ـ فلما كان ذلك يلتبس أجابوه على اللفظ ولم يلتفت للمعنى )) ( ابن عصفور 1999ج

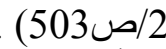

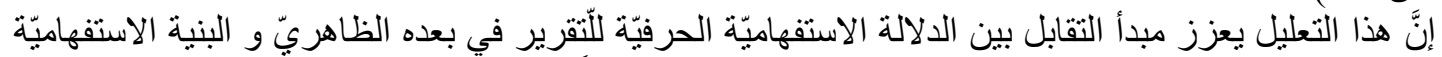

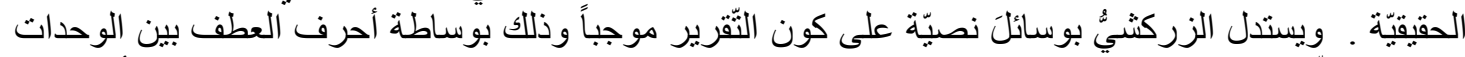

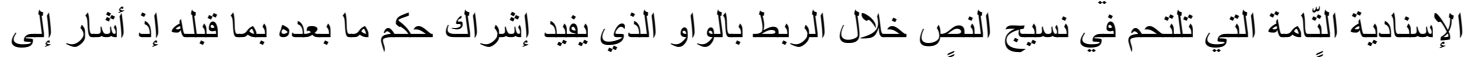

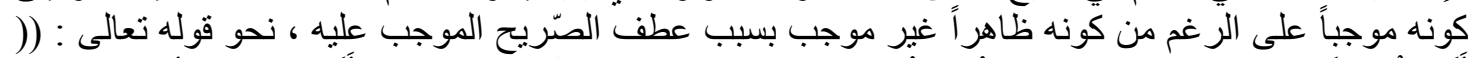

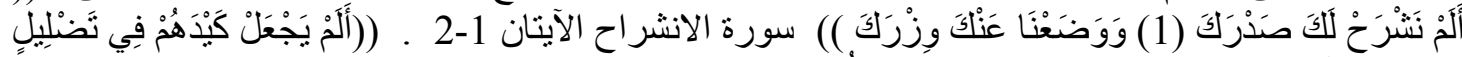

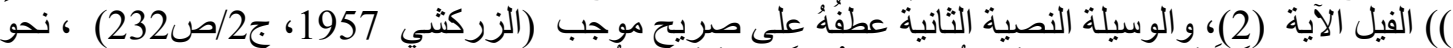

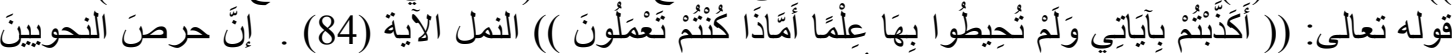

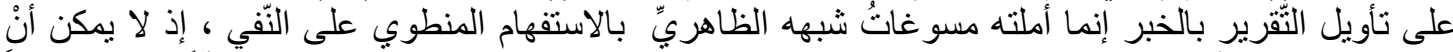

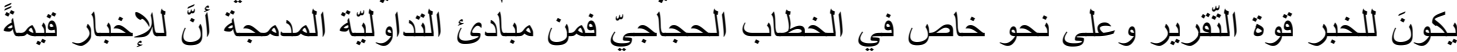

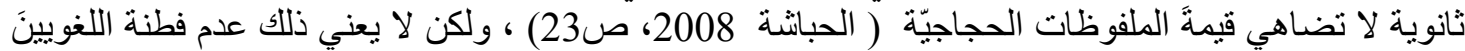

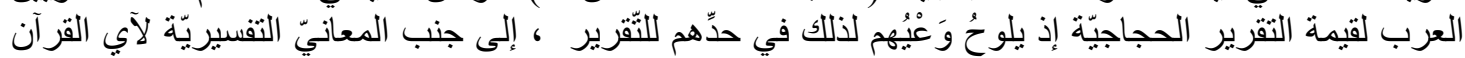

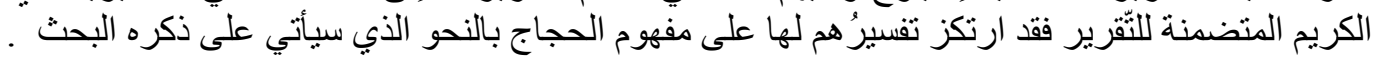

\section{المبحث الثاني : الأثر الإنجازي والبؤرة والاستلزام في التقريز}

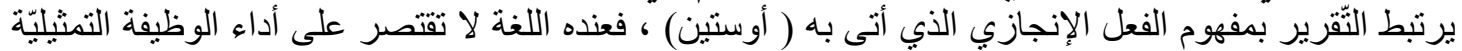

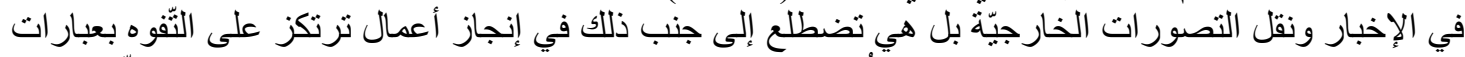

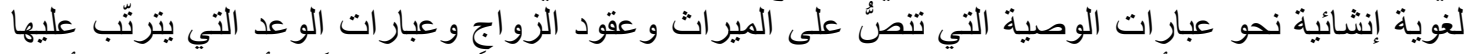

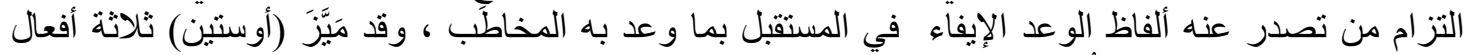

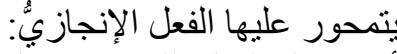

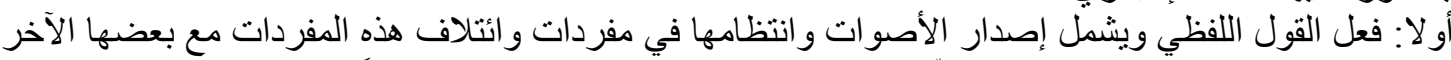

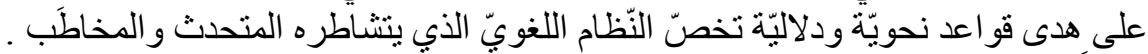

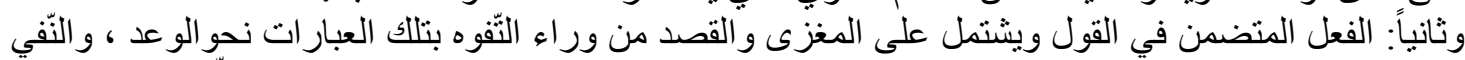

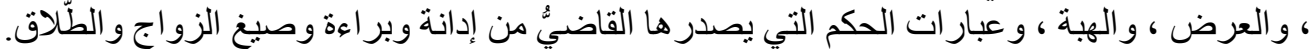

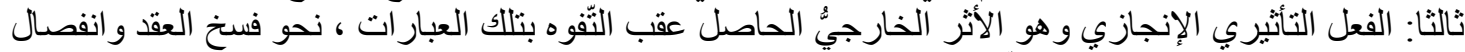

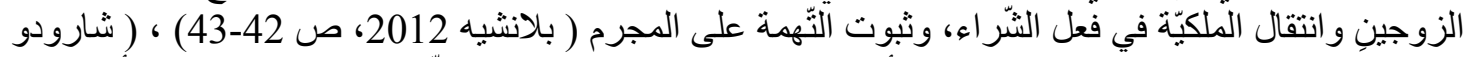

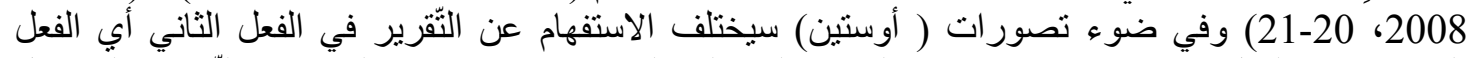

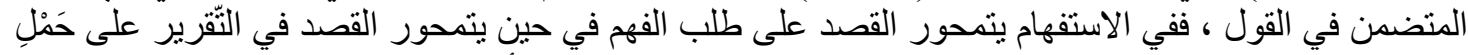

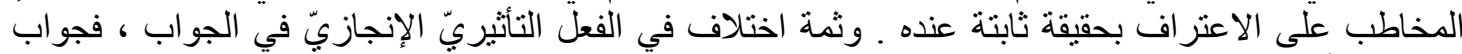

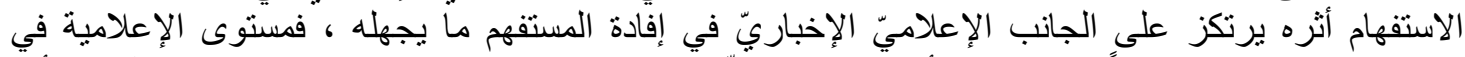

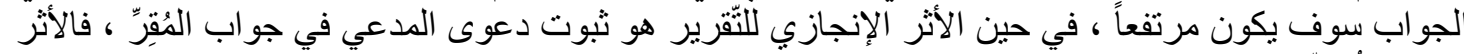

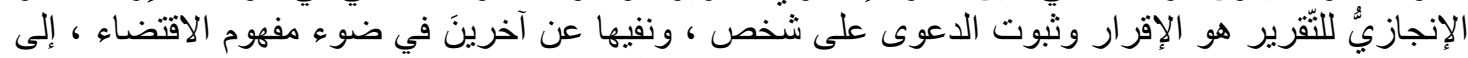

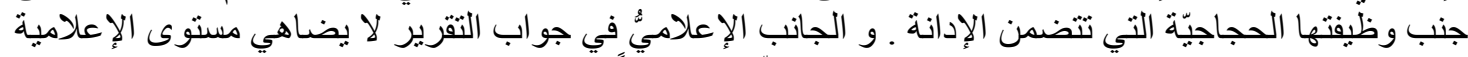

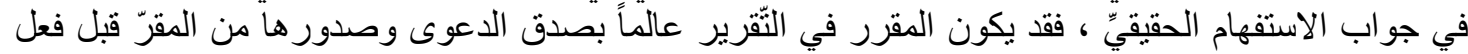

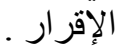

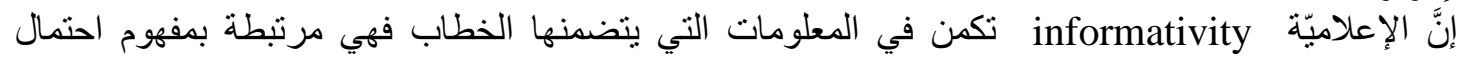

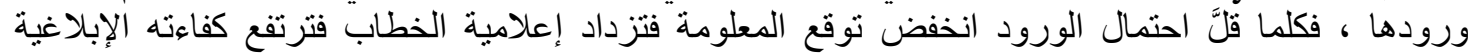

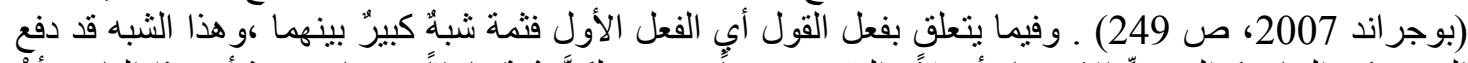

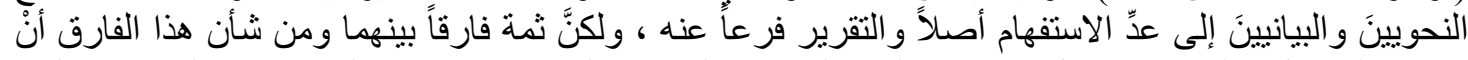

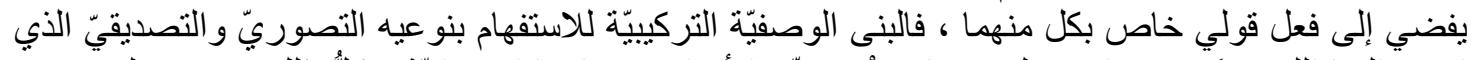

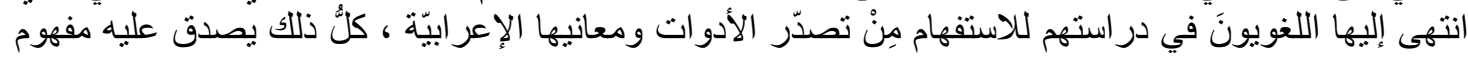




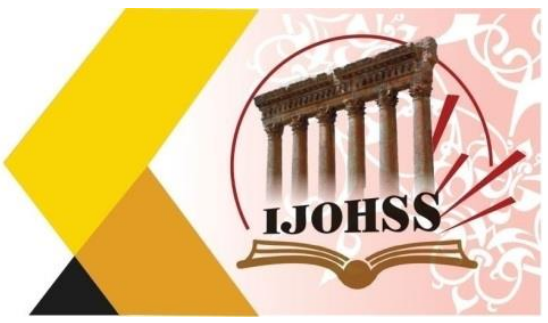

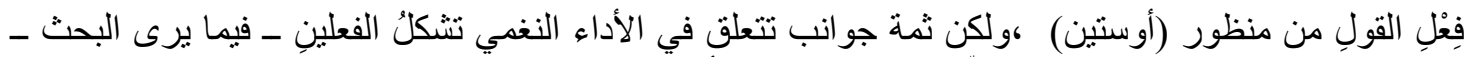

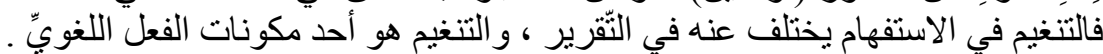

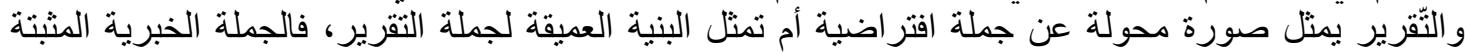

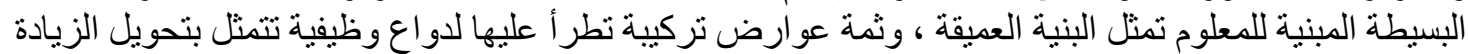

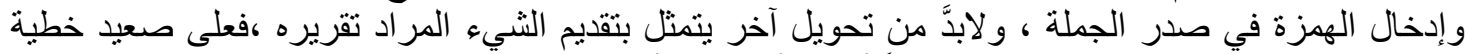

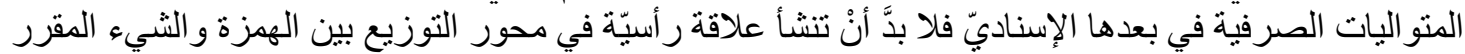

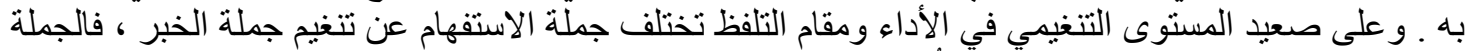

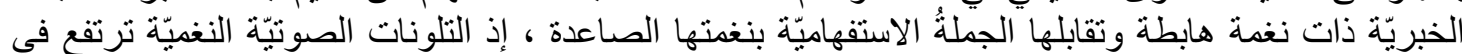

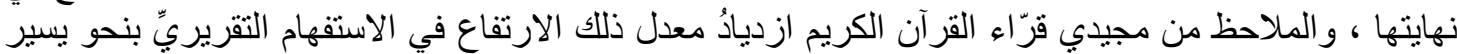

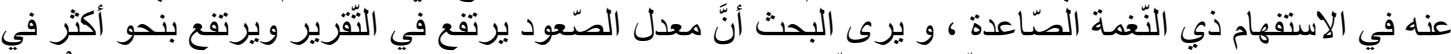

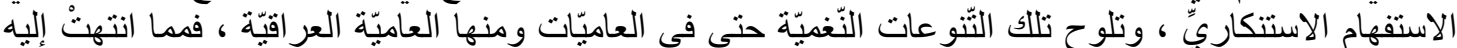

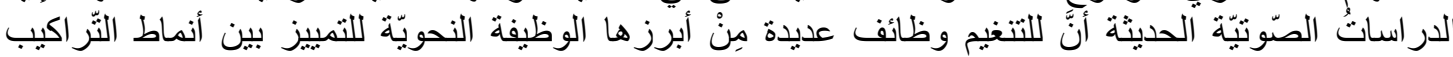

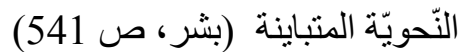

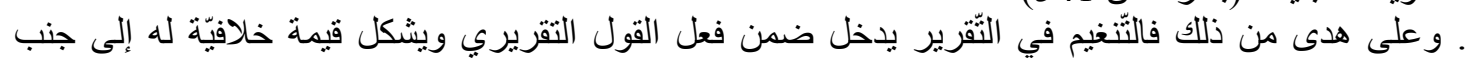
صورته التحويليّة. توزيع المقرر به ضمن بنية التقرير

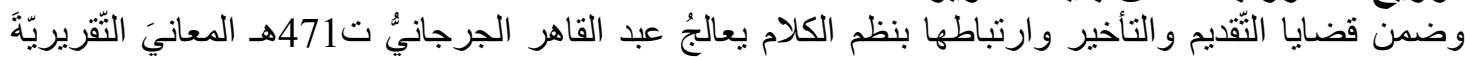

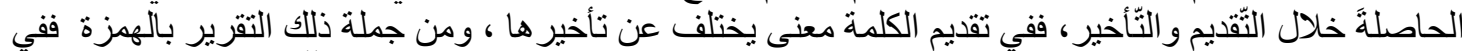

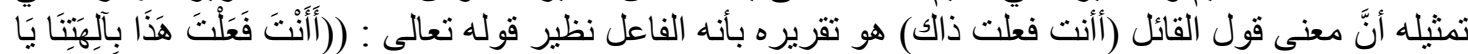

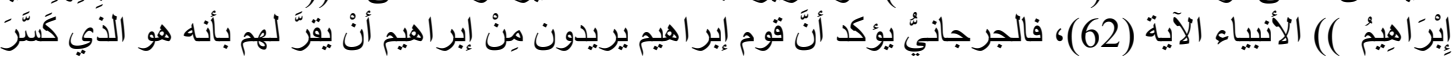

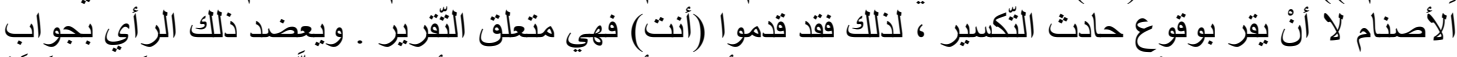

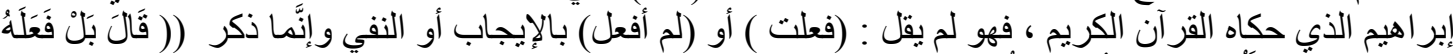

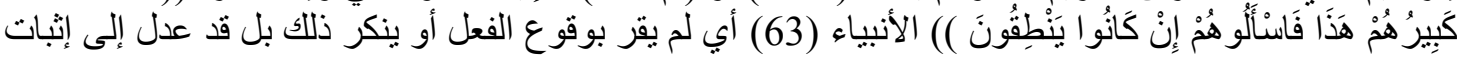

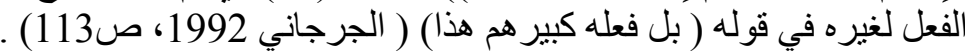

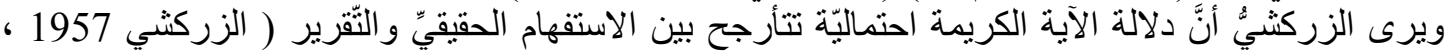

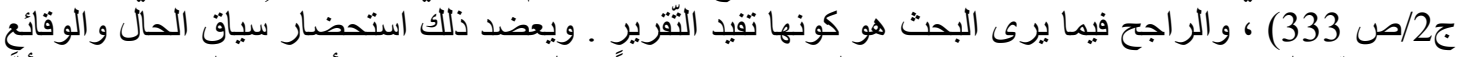

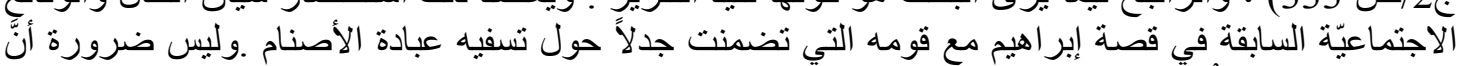

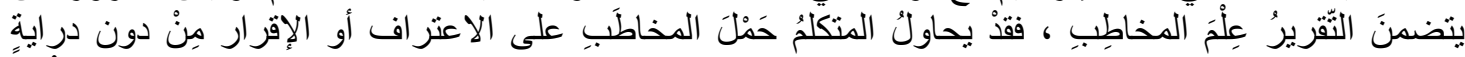

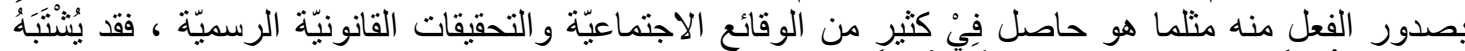

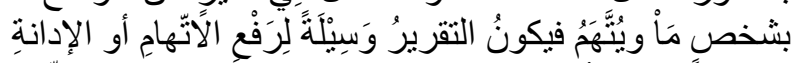

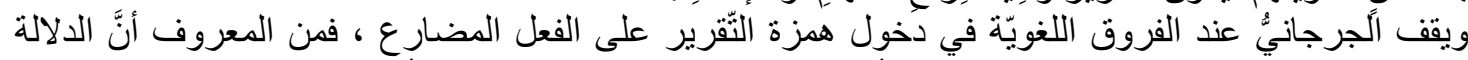

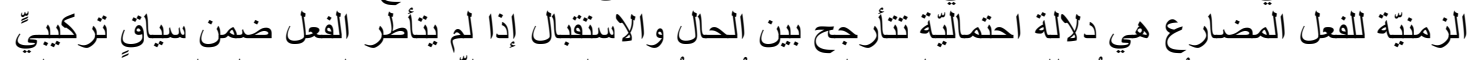

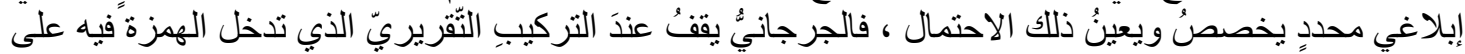

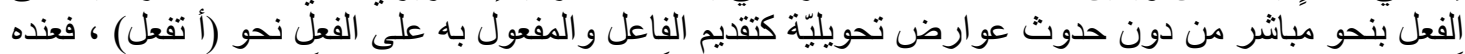

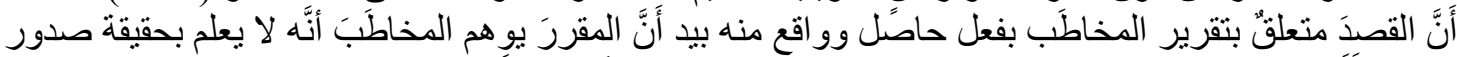

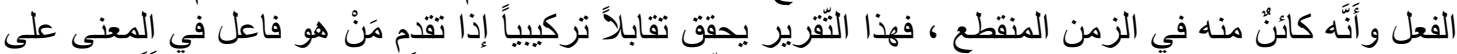

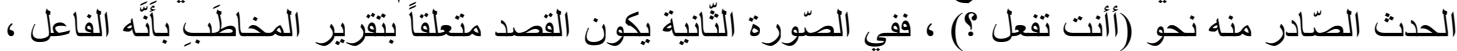

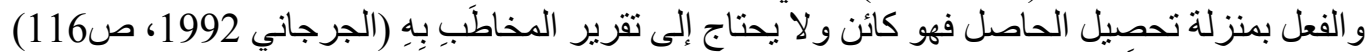

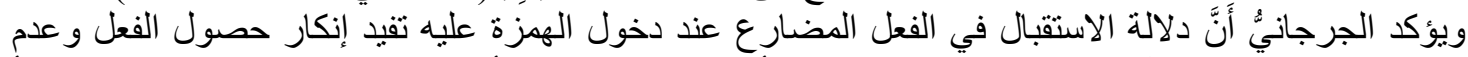

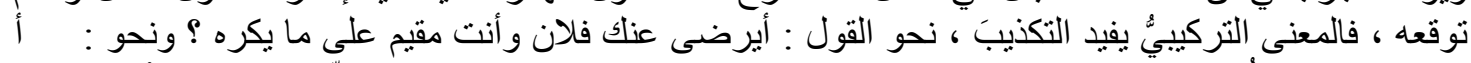

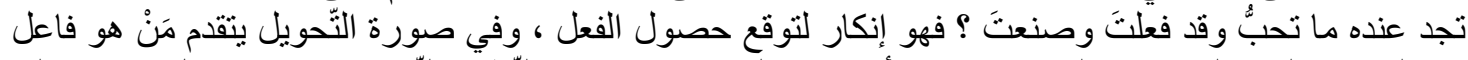

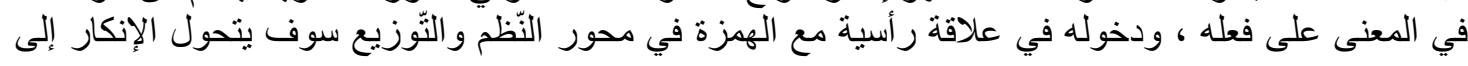




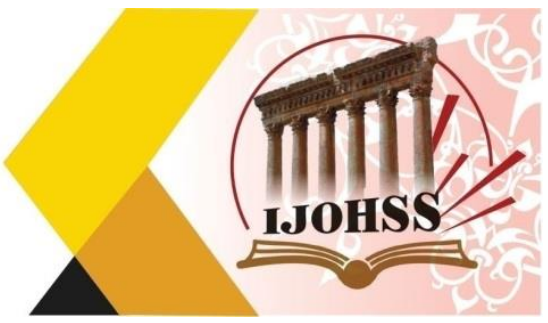

شخص الفاعل نحو : أنت تمنعني ؟ و أنت تأخذ على يدي ؟ بمعنى إنكار أصول الفعل من المخاطب ونسبته إليه

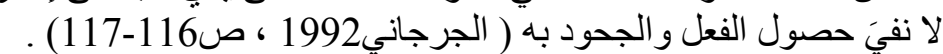

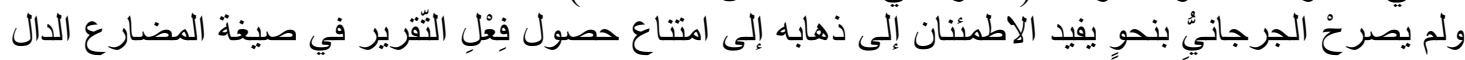

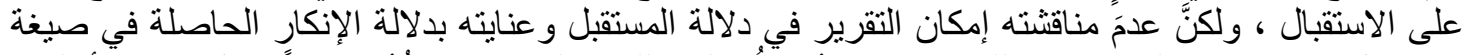

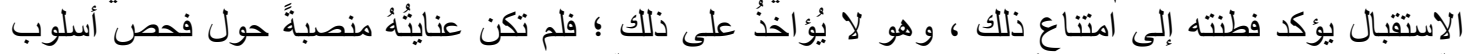

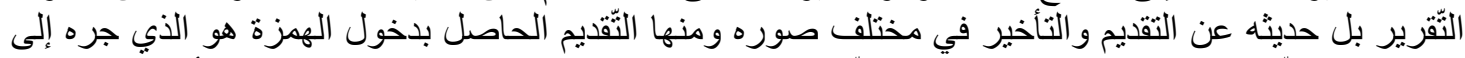

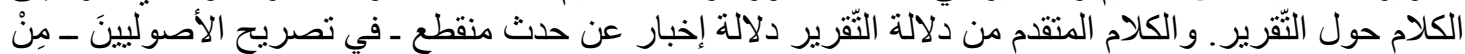

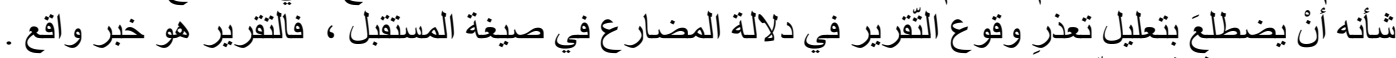

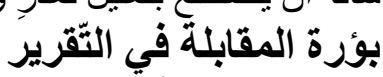

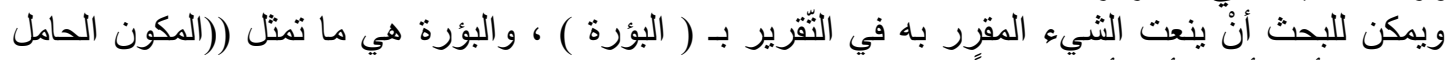

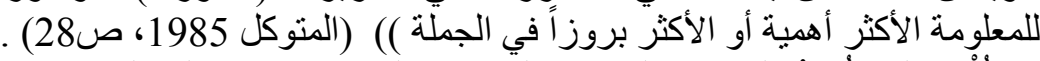

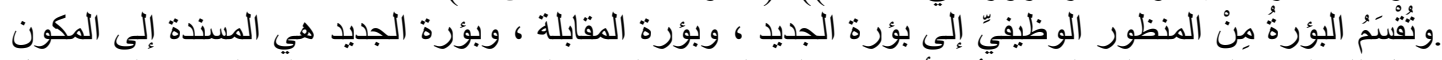

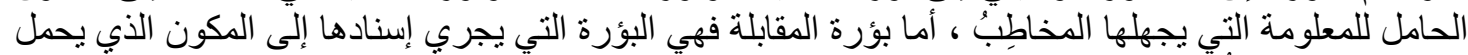

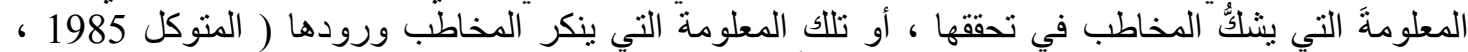

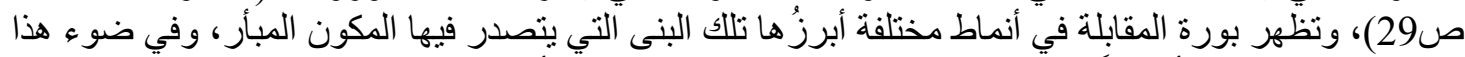

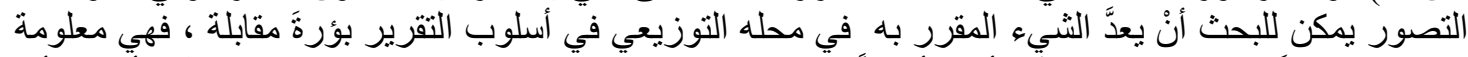

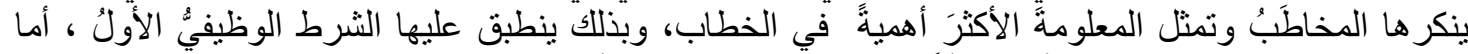

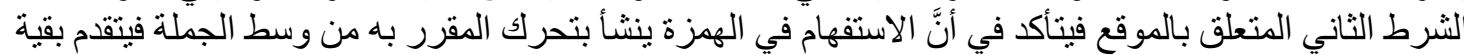

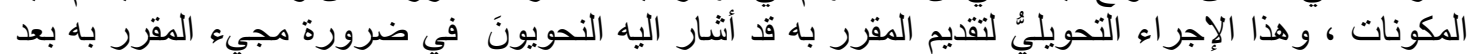

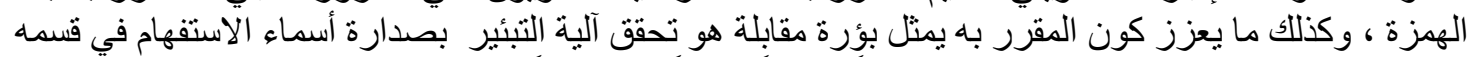

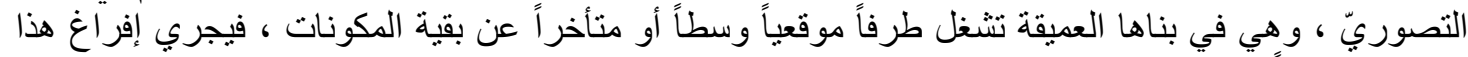

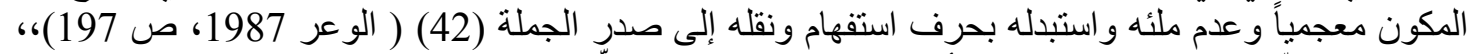

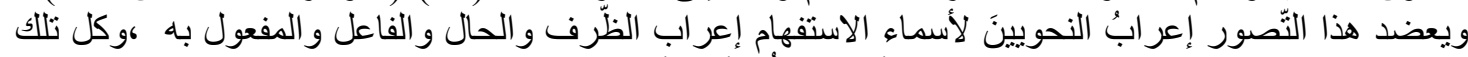

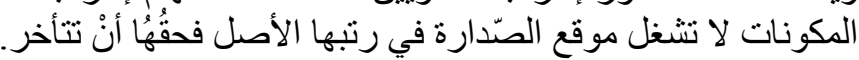

\section{الاستلزام الحواريٌّ في التّقريز ووظيقته الحجاجيّة}

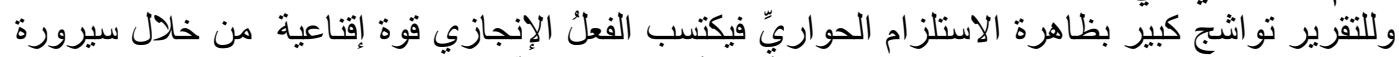

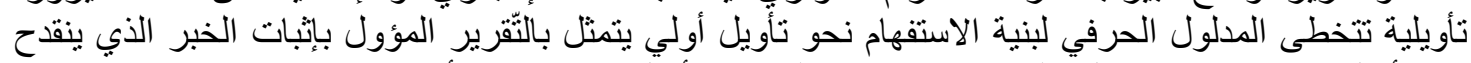

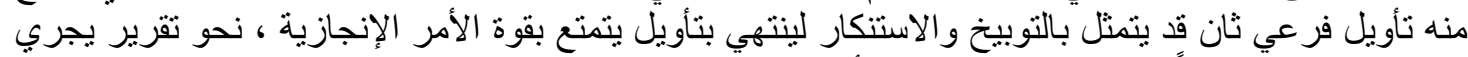

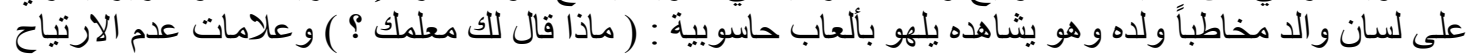

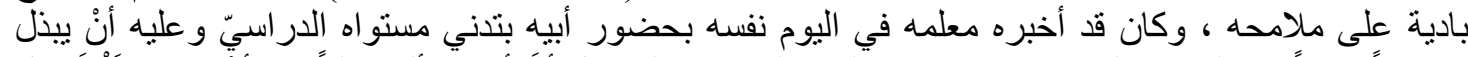

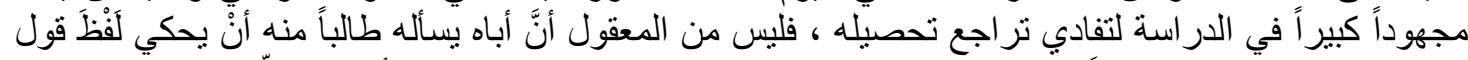

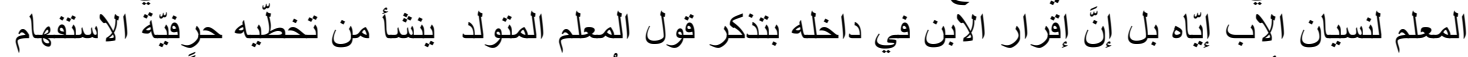

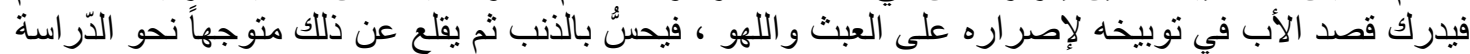

$$
\text { في فعل التأثير القوليّي }
$$

وأبرز من ربط الاستفهام بالحِجَاْج هو (ميار) فقد تبنى نظريّة المساءلة ، فالحجاج عنده ((يشتنل باعتباره ضرورة

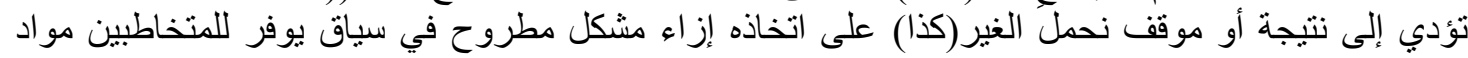

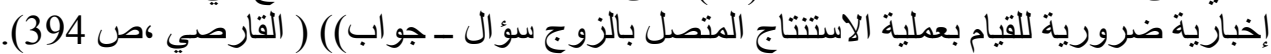

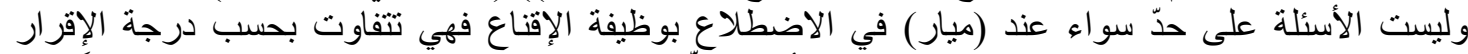

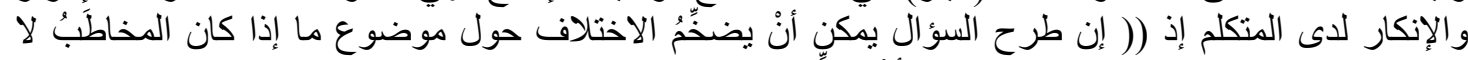

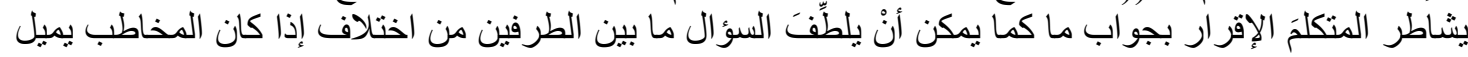




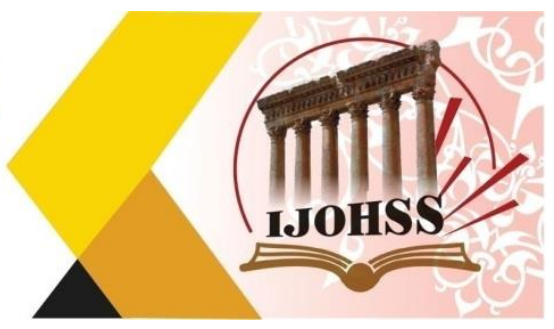

إلى الإقرار بجو اب غير جواب المتكلم ـ وبإمكان المتكلم كذلك تعميق نقاط الاتفاق مع المخاطب إذا ما كان مقراً

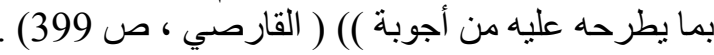

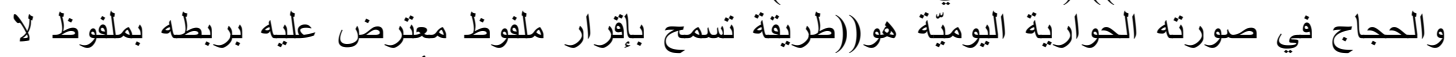

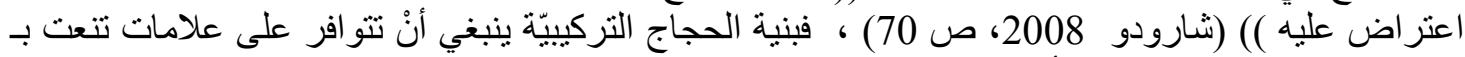

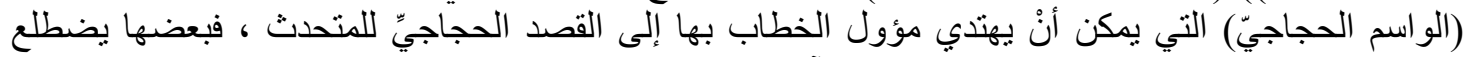

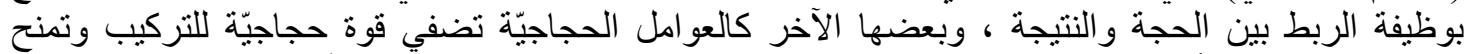

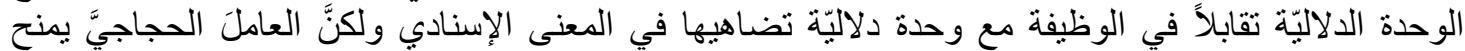

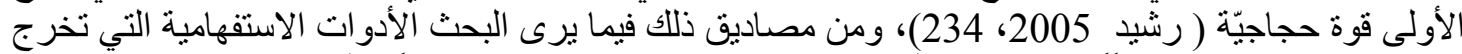

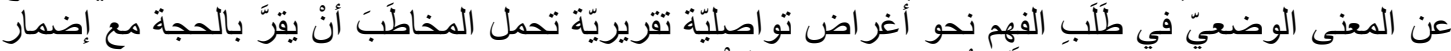

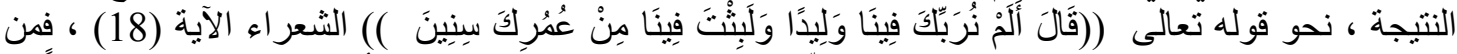

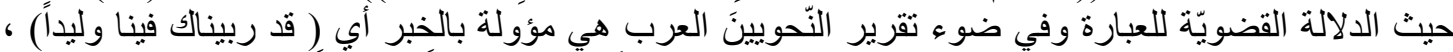

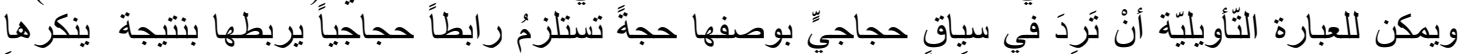

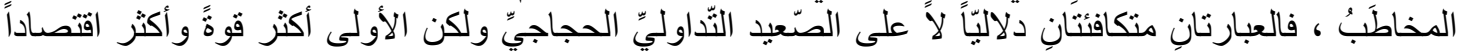

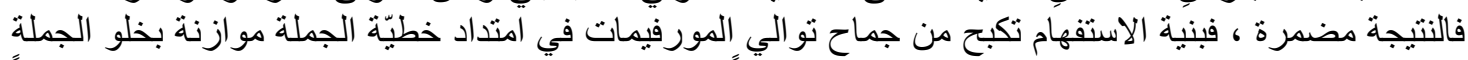

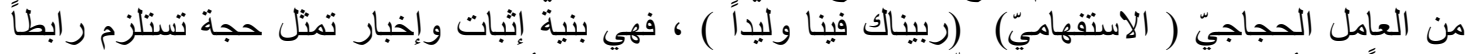

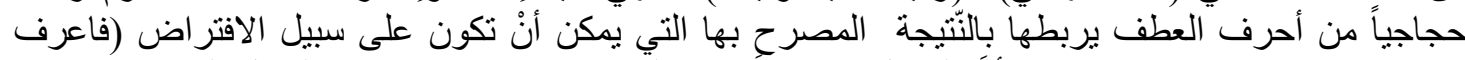

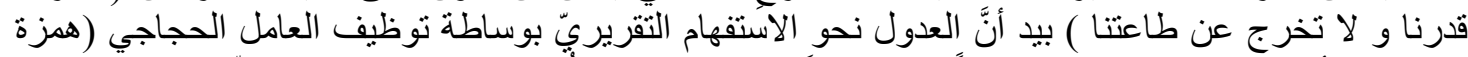

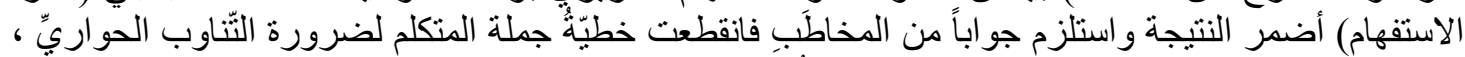

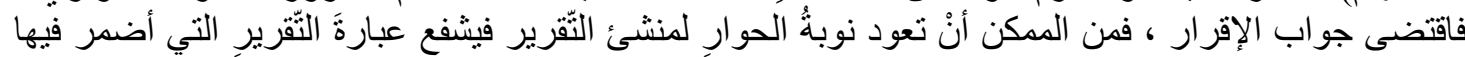

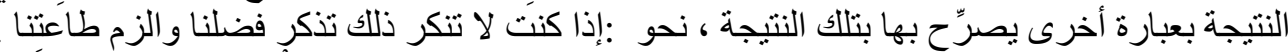

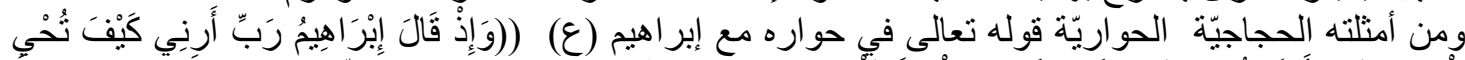

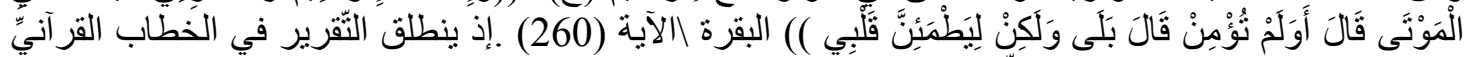

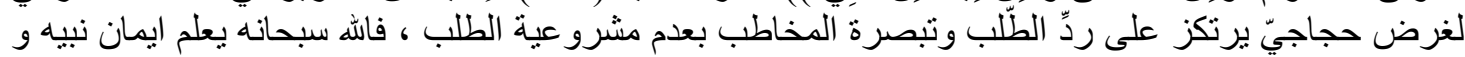

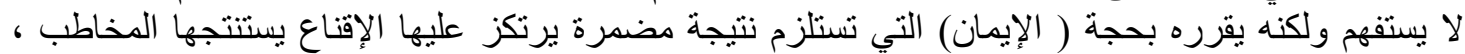

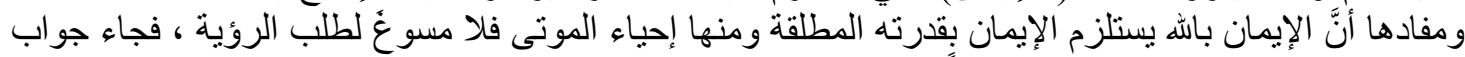

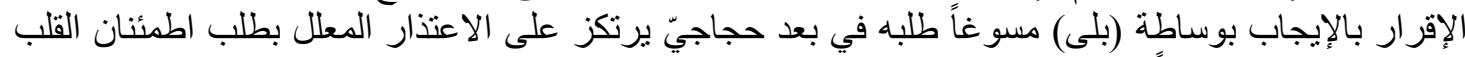

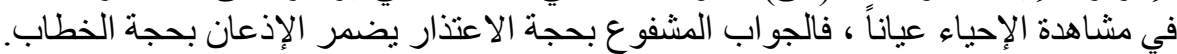

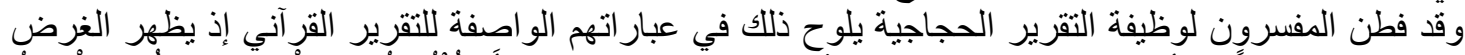

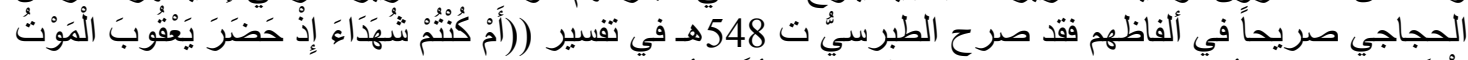

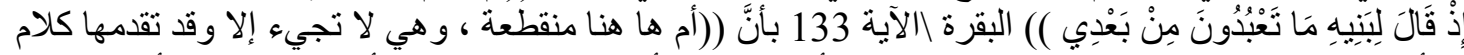

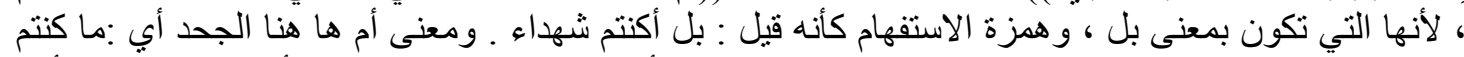

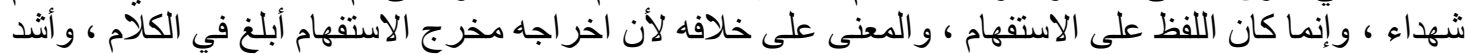

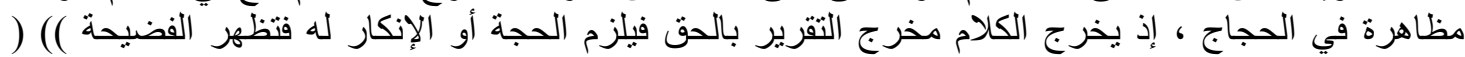

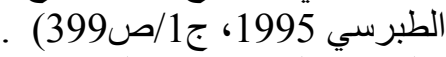

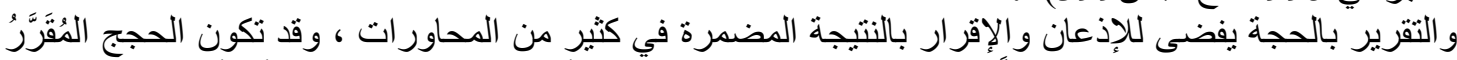

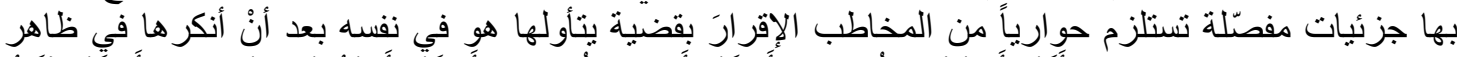

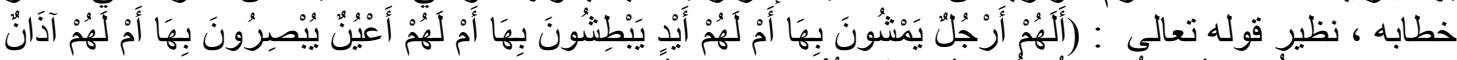

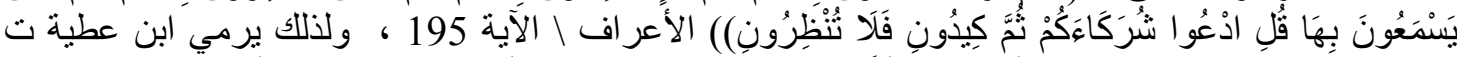

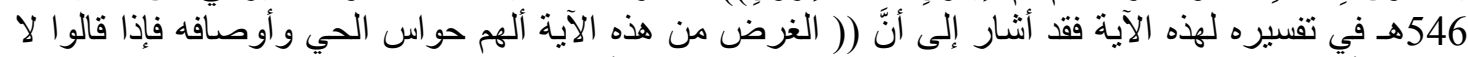

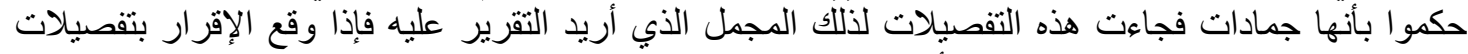

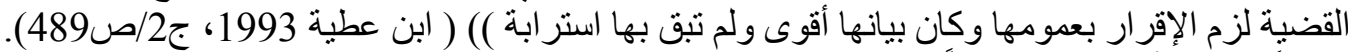

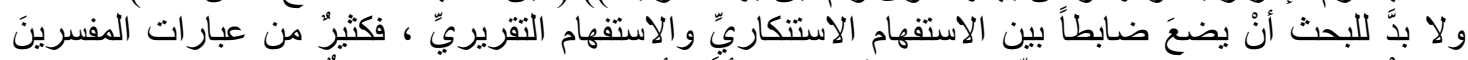

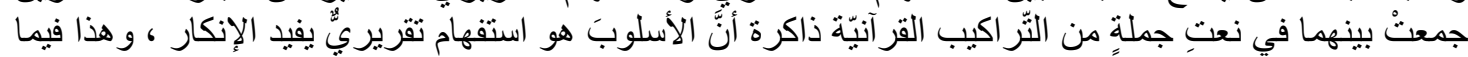




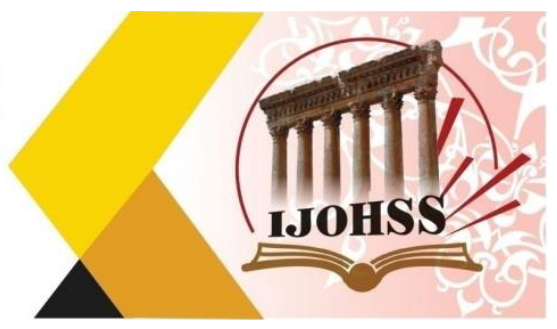

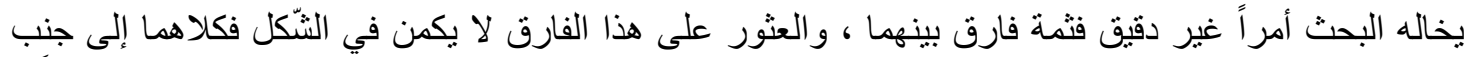

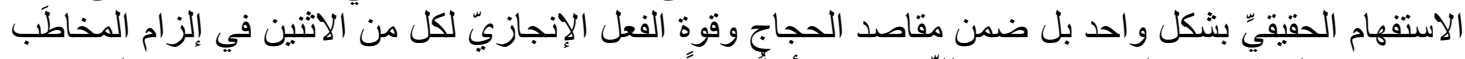

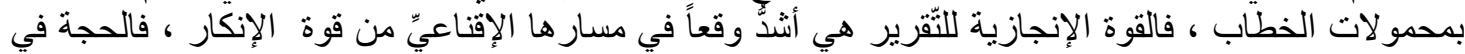

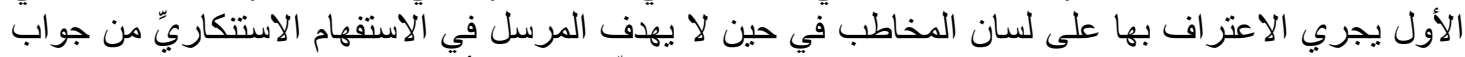

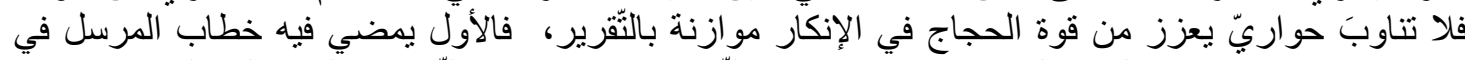

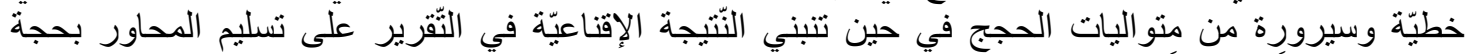

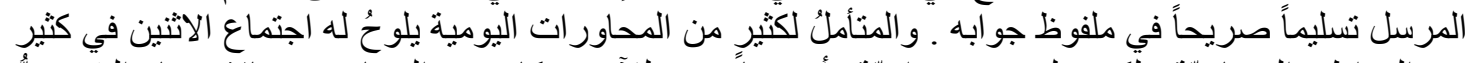

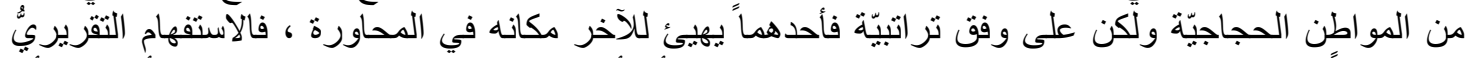

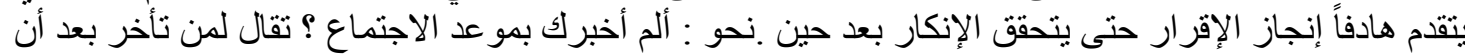

قدّم اعتذاره عن التخلف ، فيأتي الجواب بـ: بلى ، فيعقبه الاستنكار :كيف تتأخر عن موعد التحق به الجميع ؛

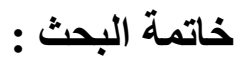

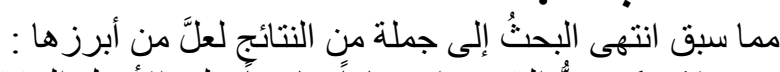

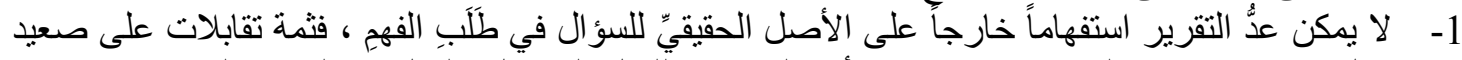

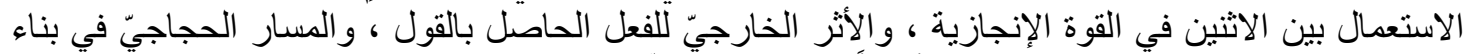

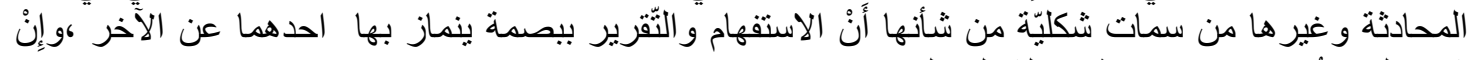

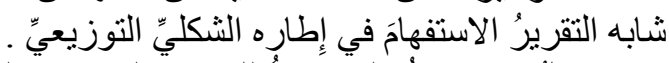

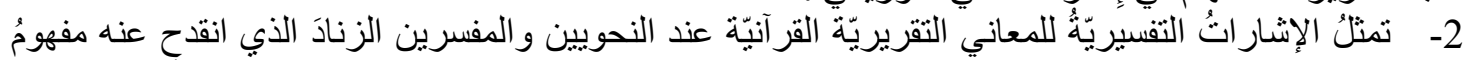

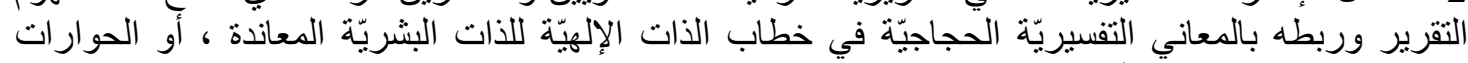

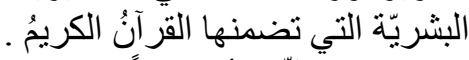

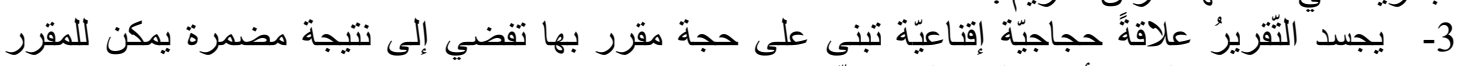

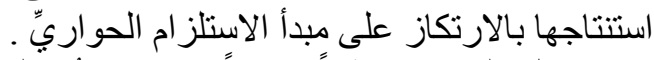

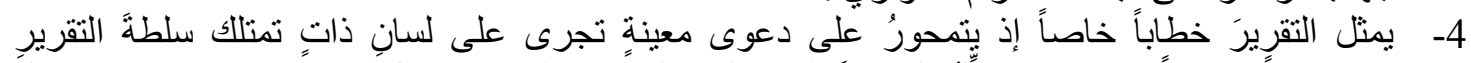

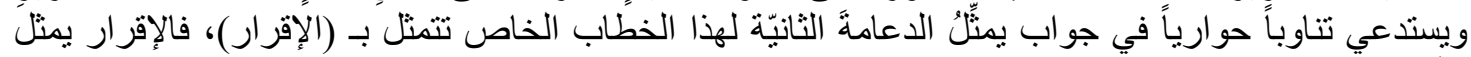

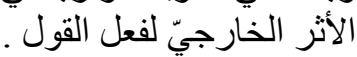

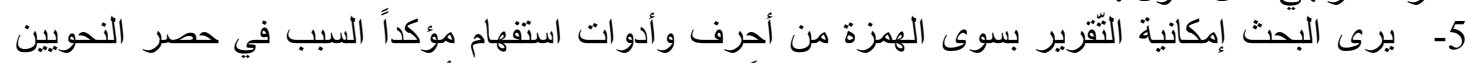

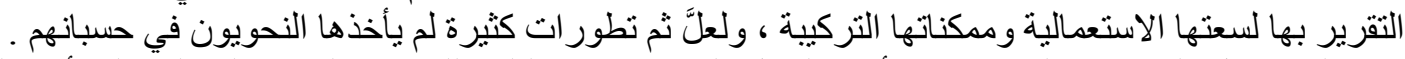

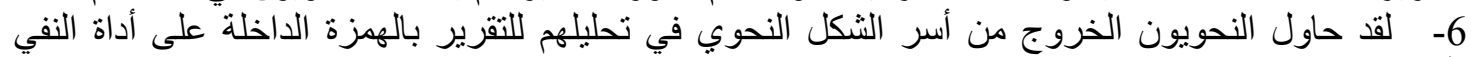

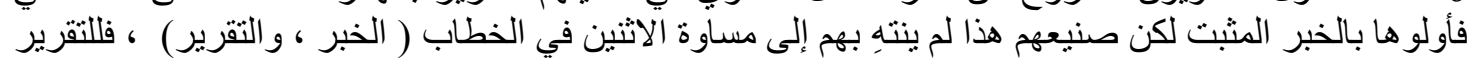

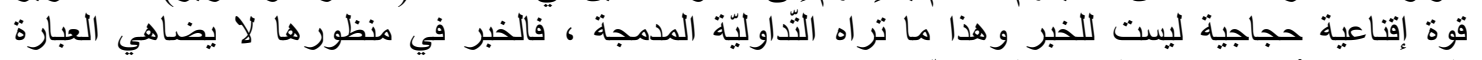

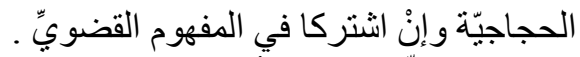

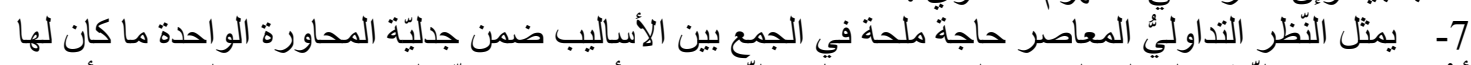

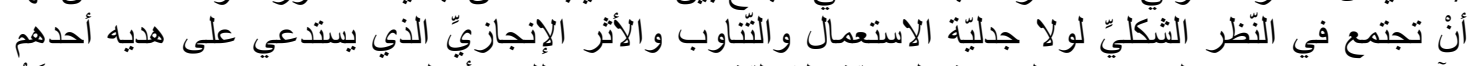

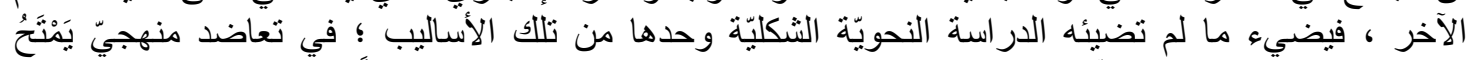

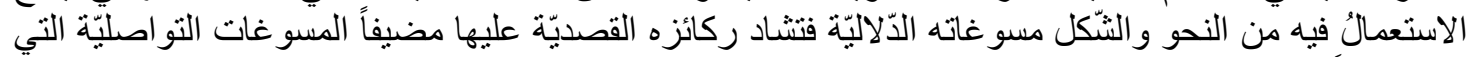
تعطي فيماً خلافيّة للتر اكيب التي تبدو متشابهة أو ينز عالحة أحدهما أنْ يكون أصلا للآخر في الثنّكل 


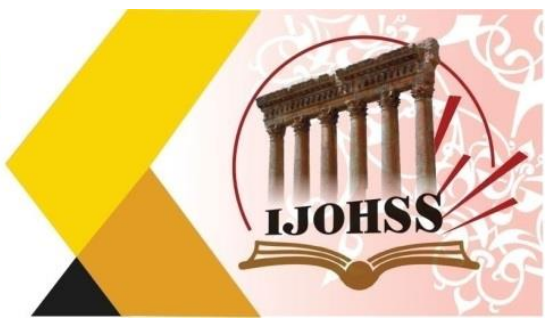

| (المصادر

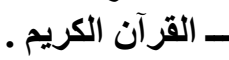

1. - ابن جني (2003)الخصائص ـ تحقيق عبد الحميد هنداوي ـ دار الكثب العلمية ـ بيروت. لبنان ـ الطبعة الثانية.

2. ـ ابن السر اجة ، أبو بكر البغدادي( 1996) الأصول في النحو ـ تحقيق عبد الحسين الفتلي مؤسسة الرسالة .

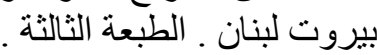
3. - ابن عطية ، الاندلسي ، (1993) ، المحرر الوجيز في تفسير الكتاب العزيز. تحقيق عبد السلام الثشافي

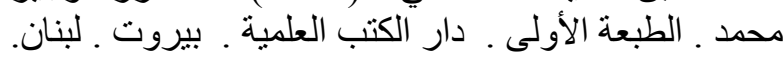

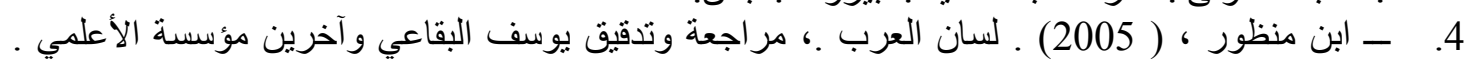

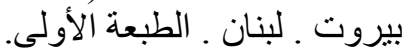
5. - ابن هشام ، الانصاري ـ مغني اللبيب عن كتب الأعاريب .. تحقيق محمد محي الدين عبد الحميد ـ المكتبة

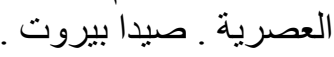

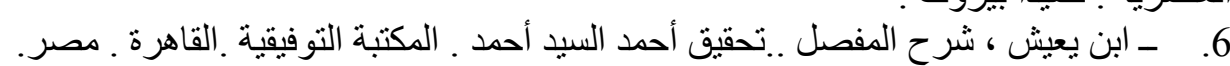

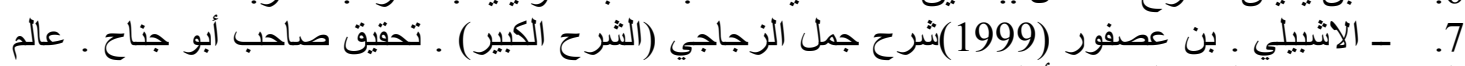

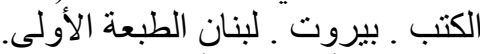
8. ـ الأندلسي ، أبو حيان ( 2001) ، البحر المحيط ..تحقيق عادل أحمد عبد الموجود وآخرون . الطبعة

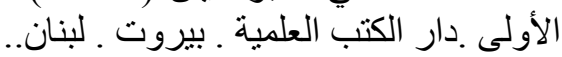
9. ـ الأوسي ، قيس إسماعيل (1988) أساليب الطلب عند النحويين والبلاغيين ـ منشورات ـ بيت الحكمة .

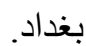

10. - بشر ، كمال .علم الأصوات ـ نثر دار غريب ـ القاهرة بدون تأريخ الطبع و رقم الطبعة.

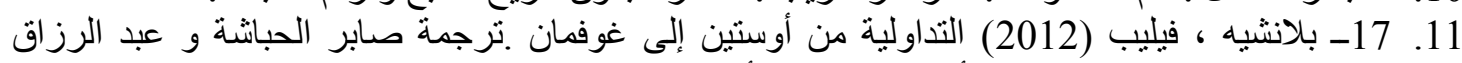

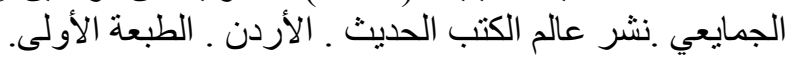
12. - ـبوجر اند ، روبرت دي (2007) ، النّص و الخطاب والإجر اء ـ ترجمة تمّام حسًّان ـ عالم الكتب القاهرة .

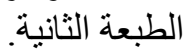
13. - الجرجاني ، عبد القاهر ( 1992) ، دلاثل الإعجاز ـ ق قراءة وتعليق محمود محمد شاكر. نشر مطبعة

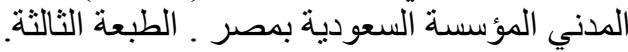

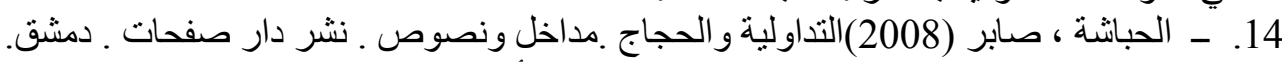

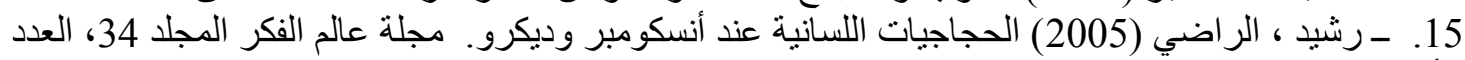

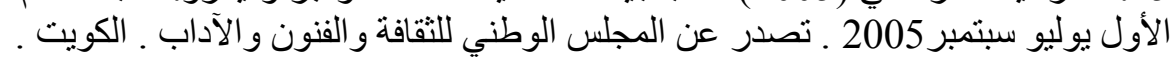
16. ـالزركثي ( 1957) البرهان ـ تحقيق محمد أبو الفضل ابر الهيم ـ دار إحياء الكتب العربية ـ عيسى البابي

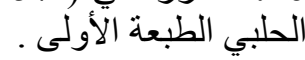
17. - ـ سيبيويه ـ الكتاب ـ تحقيق عبد السلام هارون ـ دار الجيل ـ بيروت ـ لبنان ـ الطبعة الأولى بدون تأريخ

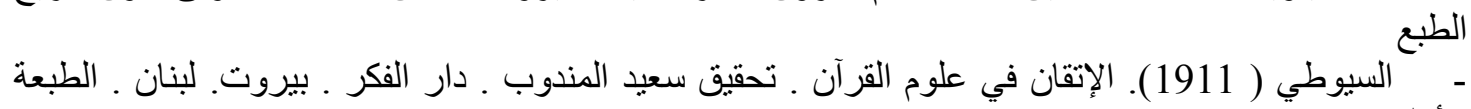

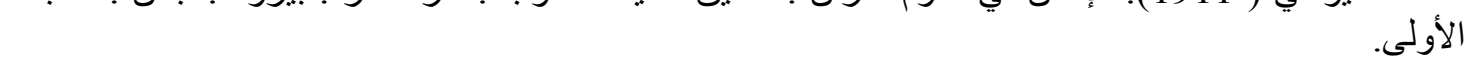
18. ـ شارودو باتريك ، منغنو دومينيك ، (2008) ، معجم تحليل الخطاب .ترجمة عبد القاهر المهيري و

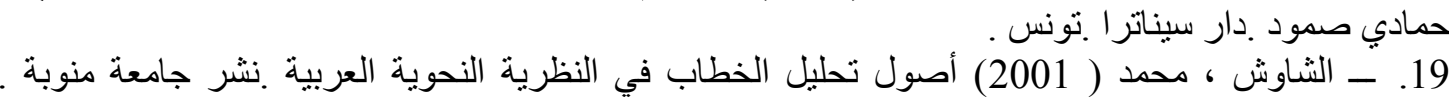
تونس. 20. - الثهري ، عبد الهادي بن ظافر (2004) استراتيجيات الخطاب .مقاربة لغوية تداولية .. دار الكتاب

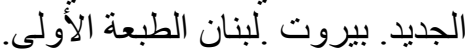
21. - الطبرسي (1995)، مجمع البيان ـ مؤسسة الأعلمي ـ بيروت ـ الطبعة الأولى. 


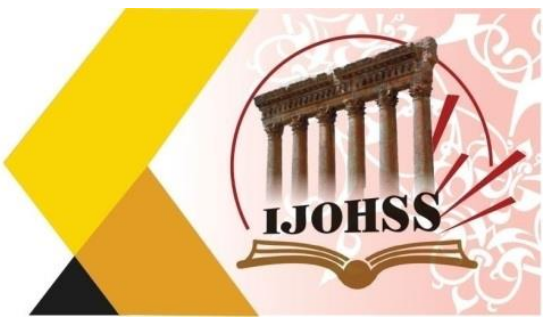

22. ـ ـ عادل ، عبد اللطيف ( 2013) ، بلاغة الإقناع في المناظرة . منشور ات ضفاف ـ منشورات الاختلاف .

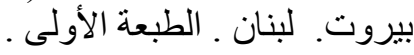

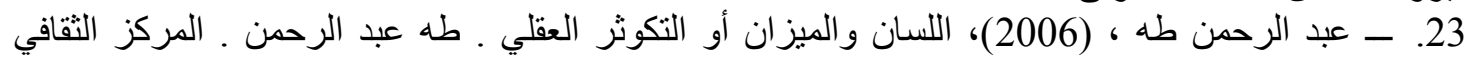

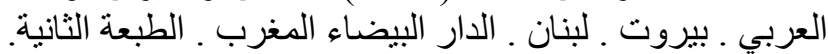

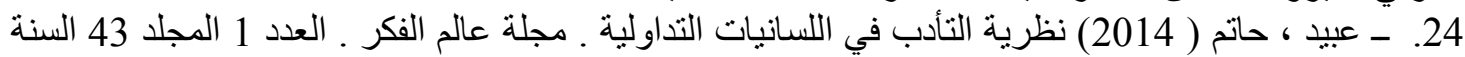

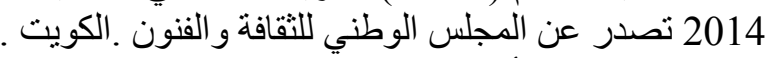
25. ـ الفار ابي ، أبو نصر (2004) ـ كتاب الحروف . تحقيق محسن مهدي ـ دار المشرق ـ بيروت ـ لبنان .

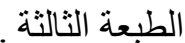

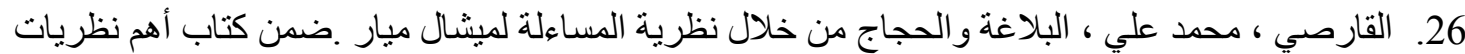
الحجاج في التقاليد الغربية من أرسطو إلى اليوم ـ إثراف حمادي صمود نشر جامعة الآداب و الفنون و العلوم

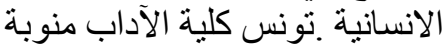

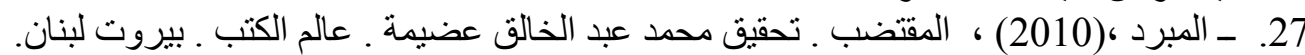

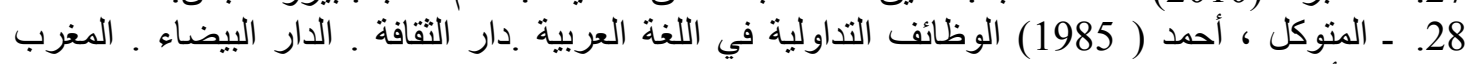

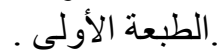

29. ـ ـ المخزومي ، مهدي (20005)، في النحو العربي نقد وتوجيه ـ دار الثَّؤون الثقافية ـ بغداد ـ الطّبعة الثانية. 30. - المرادي (1992) الجني الداني في حروف المعاني، تحقيق فخر الدين قباوة ومحمد نديم فاضل .دار

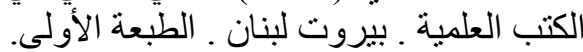

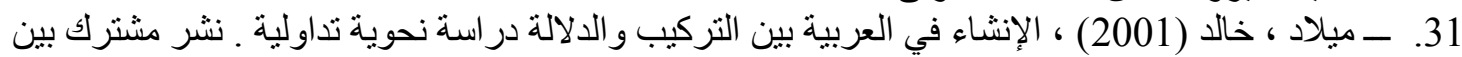

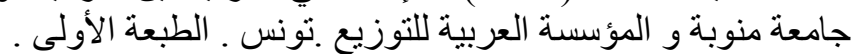

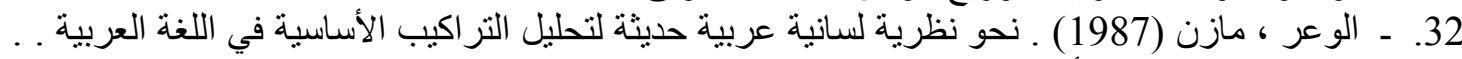
دار طلاس .دمثق ـ الطبعة الأولى .

\section{References}

\section{The Holy Quran .}

1. Abd al-Rahman Taha, (2006), The Tongue and the Scale or the Mental Generation . Taha Abdul Rahman . Arab Cultural Center. Beirut. Lebanon. Dar AlBayda', Morocco . Second edition .

2. Adel, Abdel Latif (2013), The Rhetoric of Persuasion in the Debate . Dhifaf Publications . Divergence Publications . Beirut . Lebanon . First edition .

3. Al-Andalusi, Abu Hayyan (2001) , Al-Bahr Al-Muhit .. investigated by Adel Ahmed Abdel-Mawgoud and others . First edition . Scientific Books House . Beirut . Lebanon ..

4. Al-Awsi, Qais Ismail (1988) The Methods of Demand among Grammarians and Rhetorics . Publications . House of wisdom . Baghdad .

5. Al-Farabi, Abu Nasr (2004). Book of Letters : Mohsen Mahdi's Investigation . AlMashriq House . Beirut . Lebanon . Third edition .

6. Al-Habasha, Saber (2008) Pragmatics and al-Hajjaj : Entries and Texts . Safahat Publishing House P . Damascus .

7. Al-Ishbily . Bin Asfour (1999) Explanation of Al-Zajaiji Sentences (The Great Explanation ). Abu Jinnah's Investigation. The world of books . Beirut . Lebanon. First edition . 


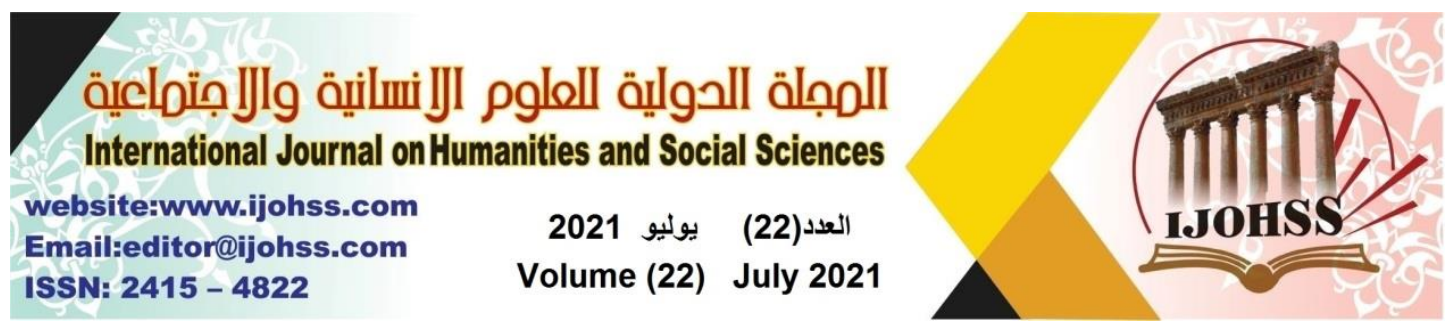

8. Al-Jarjani, Abdel-Qaher (1992) , Evidence of Miracles . Reading and commenting by Mahmoud Muhammad Shaker . Published by Al-Madani Press, the Saudi Foundation in Egypt . Third edition .

9. Al-Makhzoumi, Mahdi (20005), in Arabic Grammar, Criticism and Direction . House of Cultural Affairs . Baghdad . Second edition .

10. Al-Mubarid, (2010) , Succinct . Investigated by Muhammad Abdul Khaleq Adaymeh . The world of books . Beirut, Lebanon .

11. Al-Mouradi (1992) The Proximal Genie in the Letters of Maani, edited by Fakhr al-Din Qabawa and Muhammad Nadim Fadel . Scientific Books House . Beirut, Lebanon . First edition .

12. Al-Mutawakel, Ahmad (1985) Pragmatic Functions in the Arabic Language . House of Culture . Al-dar Al-Bayd' . Morocco . First edition .

13. Al-Qarsi, Muhammad Ali," Rehtoric and Protest through Michel Mayar's The Accountability Theory" in the book of The Most Important Theories of Protest in the Western Tradition from Aristotle to Today . Supervised by Hammadi Samoud University of Arts, Fine Arts and Human Sciences publishing . Tunisia College of Arts Manouba

14. Al-Shawash, Muhammad (2001) The Origins of Discourse Analysis in Arabic Grammatical Theory . Manouba University Publishing . Tunisia .

15. Al-Shehri, Abd al-Hadi bin Dhafer (2004) Discourse Strategies : A Pragmatic Linguistic Approach .. Dar Al-Kitab Al-Jadeed . Beirut . Lebanon first edition .

16. Al- Suyuti (1911). Perfection in the Sciences of the Qur'an . Saeed Al-Mandoub investigation. Thought House . Beirut . Lebanon . First edition .

17. Al-Tabarsi (1995), Majma 'al-Bayan . Al-Alamy Foundation . Beirut . First edition .

18. Al-Waer, Mazen (1987). Towards a Modern Arabic Linguistic Theory to Analyze the Basic Structures in the Arabic Language . . Tlass House . Damascus . First edition

19. Al-Zarkashi (1957) The Proof . Achieved by Muhammad Abu Al-Fadl Ibrahim . House of Revival of Arabic Books - Issa Al-Babi Al-Halabi, first edition .

20. Ibn al-Sarraj, Abu Bakr al-Baghdadi (1996) Origins in Grammar . Investigated by Abdul Hussein Afattly. Al-Risala Foundation. Beirut, Lebanon . Third edition .

21. Ibn Atiyah, Al-Andalusi, (1993), the Brief Editor in the Interpretation of the Holy Quran . Investigated by Abdul Salam Al Shafi Muhammad . First edition . Scientific Books House. Beirut . Lebanon .

22. Ibn Hisham, Al-Ansari . Mughni Al-Labib on the Books of Al-A rib `, edited by Muhammad Mohiuddin Abdel-Hamid . The modern library . Sida, Beirut .

23. Ibn Jinni (2003) Characteristics . Investigated by Abdul Hamid Hindawi . Scientific Books House . Beirut . Lebanon . Second edition .

24. Ibn Manzur, (2005). The Tongue of the Arabs . Reviewed and edited by Yusef AlBuqai and others. Al-Alami Foundation . Beirut . Lebanon . First edition .

25. Ibn Yaish, Explanation of Al-Mufasal. Investigated by Ahmed Al-Sayed Ahmed . Al-Tawfiqia Library . Cairo . Egypt . 
26. Bishr, Kamal . Phonology . Ghareeb Publishing House. Cairo without printing date and edition number .

27. Blanche, Philip (2012) Pragmatics from Austin to Goffman . Translated by Saber Al-Habasha and Abdul Razzaq Al-Juma'i . Modern Book World Publishing . Jordan . First edition .

28. Bojrand, Robert D. (2007) , Text, Discourse, and Procedure . Translated by Tammam Hassan . World of Books Cairo . Second edition .

29. Milad, Khaled (2001) , Composition in Arabic between the Structure and Significance of Pragma- Syntactic Study . A joint publication between Manouba University and the Arab Association for Distribution . Tunisia . First edition .

30. Obaid, Hatem (2014) The Theory of Politeness in Pragmatics. Thought World Magazine . Issue 1, volume 43, year 2014, issued by the National Council for Culture and Arts . Kuwait .

31. Patrick, Charodu, Mangano Dominic, (2008), The Dictionary of Discourse Analysis ... translated by Abdul Qaher Al Muhairi and Hammadi Samoud . Sinatra House . Tunisia .

32. Rashid, Al-Radi (2005)" Linguistic Protests of Anscomber and Decro" in The World of Thought Magazine. Volume 34, Issue 1 July, September 2005. Issued by the National Council for Culture, Arts and Letters . Kuwait .

33. Sibawayh . The Book . Investigated by Abdul Salam Haroun . Generation House . Beirut . Lebanon . First edition . 